Portland State University

PDXScholar

$1-1-2010$

\title{
Investing and Vesting International Students' Expressive Resources in Social Capital at Portland State University
}

Mami Kikuchi

Portland State University

Follow this and additional works at: https://pdxscholar.library.pdx.edu/open_access_etds Let us know how access to this document benefits you.

\section{Recommended Citation}

Kikuchi, Mami, "Investing and Vesting International Students' Expressive Resources in Social Capital at Portland State University" (2010). Dissertations and Theses. Paper 130.

https://doi.org/10.15760/etd.130

This Thesis is brought to you for free and open access. It has been accepted for inclusion in Dissertations and Theses by an authorized administrator of PDXScholar. Please contact us if we can make this document more accessible: pdxscholar@pdx.edu. 
Investing and Vesting International Students’ Expressive Resources in Social Capital

\author{
at Portland State University
}

by

Mami Kikuchi

A thesis submitted in partial fulfillment of

the requirement for the degree of

\author{
Master of Arts \\ in \\ Communication
}

Thesis Committee:

Cynthia-Lou Coleman, Chair

Priya Kapoor

Yves Labissiere

Portland State University

(C) 2010 


\begin{abstract}
The study expands the conceptual and methodological precepts of social capital by examining how international students receive social capital from their friends and how students provide social capital to their friends in a North American university setting. The author examines the degree of emotional support that the participants provide ("Investing” social capital) and the support they receive from their friends ("Vesting” social capital), and the relationships between the two social capital variables. In addition, the study examines the influence of demographics and social interaction on social capital, and the influence of social capital on satisfaction. The study suggests that vesting and investing in social capital are correlated, and that giving and receiving social capital are influenced by social interactions with friends. However, social capital offered no significant contribution to satisfaction.
\end{abstract}




\section{DEDICATION}

To my moms, Shizuko Kikuchi and Norma Gordon 


\section{ACKNOWLEDGEMENTS}

First, I would like to thank all the international students who participated in my survey. I know you are all busy studying, but took some time to do me a favor.

Without your cooperation, my study would not have been completed.

I would like to thank Dr. Cynthia-Lou Coleman. You taught me the joy of “digging deep” using my own brain instead of taking knowledge for granted. I learned the bliss of conducting research from you. Gently but steadily, you have been pushing my back to keep learning and writing. I also would like to thank Dr. Priya Kapoor and Dr. Yves Labissiere for providing wonderful feedback and inspiring me to expand my ideas and thoughts.

I thank my family and friends in Japan and Australia, and the United States. You always patiently believed in me that I could go through this long term project.

I thank all of my friends at Portland State University for helping me to survive in this academic journey. Many of you also gave me insightful feedback during my pilot study. I want to say thank you to Yoichi Sato and Dr. Masami Nishishiba who encouraged me to go through the graduate program. Without their advice, I would not have even started. I have special thanks for my thesis buddy, Celeste Moser. My thesis 
work suddenly started rolling since we began to meet regularly to chat about our progress. Your support, encouragement, and big smile always hearten me. I owe another special thanks to my study mate, Yachiyo Iisako. I cannot count how many cups of coffee we drank while studying together almost every night. You cheerfully prompted me whenever I got tired and scared of making progress. Of course, I have to also thank the wonderful coffee shop Palio in South East Portland, where I spent countless study hours for the last few years.

Last but not least, I would like to thank my husband, Russ Gordon. Thank you for always standing by me. You believed in me and believed that I could complete my graduate program even when I myself did not believe so. Without your love, support, patience, and incredible proofreading skill, I would never finish this process.

Through my thesis about social capital, I re-discovered that I have a wonderful social capital of my own, and that is the best outcome of this long term project. 


\section{TABLE OF CONTENTS}

ABSTRACT

DEDICATION ii

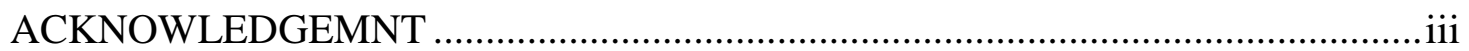

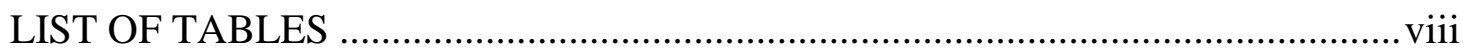

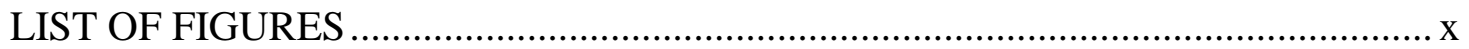

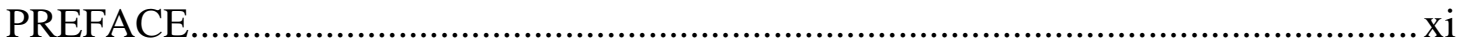

\section{CHAPTER 1}

Literature Review ....................................................................................... 1

Social Capital: History of the Concept ........................................................ 2

Categorization of Social Capital............................................................... 5

Social Capital Research in the Communication Discipline............................ 14

Social Capital Explication .......................................................................... 24

Definition of Social Capital in the Current Study ......................................... 27

\section{CHAPTER 2}

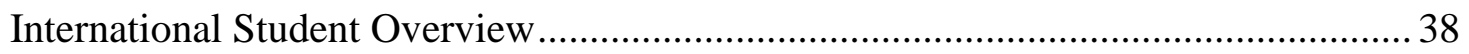

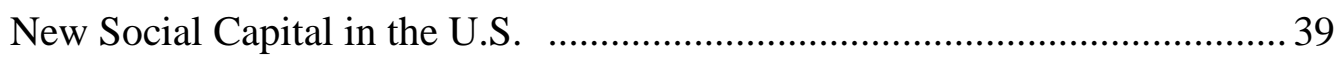

Common Issues among International Students ......................................... 40

Needs for Social Capital ........................................................................ 43

\section{CHAPTER 3}

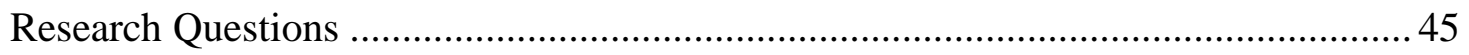

\section{CHAPTER 4}

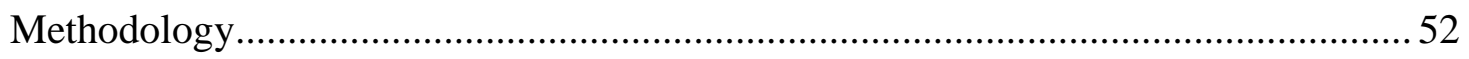


Research Design Overview .................................................................... 52

Population of the Study: Participants Criteria ................................................ 54

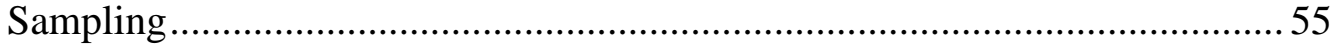

Pilot Study: Feedback from Colleagues ..................................................... 55

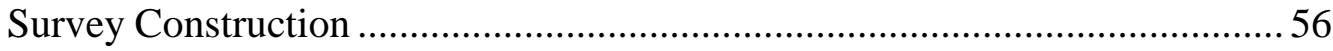

Socializing with Friends ............................................................ 57

Emotional Support from Friends ................................................... 59

Life Satisfaction at Portland State University .................................. 61

Emotional Support from the Participant to friends............................ 63

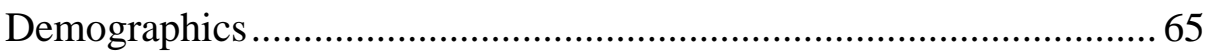

\section{CHAPTER 5}

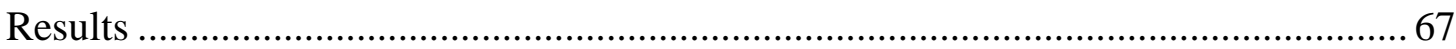

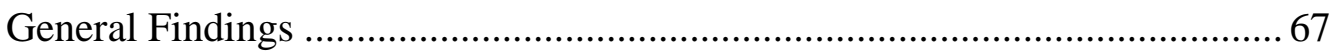

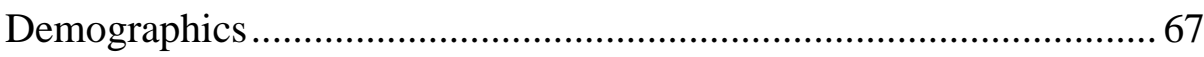

Country of Origin ............................................................. 68

Personal Attributes ….............................................................. 71

Length of Residence at Portland State University................... 71

Living Arrangements ......................................................... 71

Financial Conditions.............................................................. 73

Comfort Level in English ................................................... 74

English Proficiency ............................................................ 75

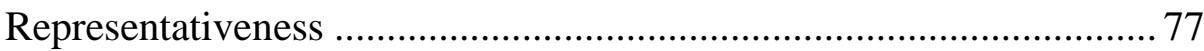

Relationship among Independent Variables.................................... 79

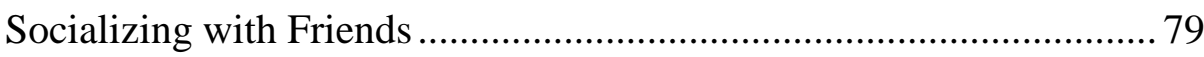

Satisfaction with Life at Portland State University ........................... 81

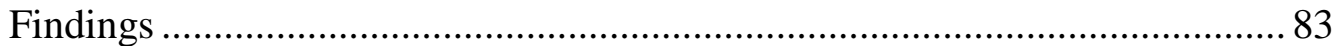

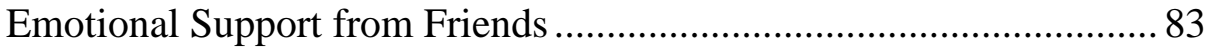

Emotional Support from the Participant............................................ 86

Relationship between Friends Support and Participant Support .......... 88

Relationship between Socializing with Friends and Friends Support .. 90 Relationship between Socializing with Friends and Participant Support 
Life Satisfaction and Friends Support ................................................ 100

Life Satisfaction and Participant Support........................................... 103

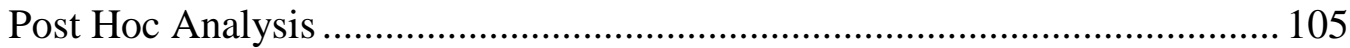

Differences in the Gap between Participant Support and Friends

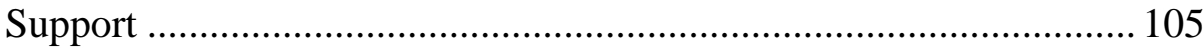

\section{CHAPTER 6}

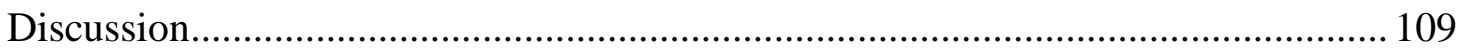

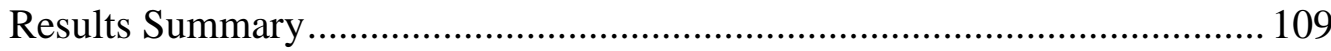

Friends Support: Vesting Expressive Resources ............................................... 111

Participant Support: Investing Expressive Resources ....................................... 112

Relationship between Investing and Vesting Expressive Resources .............. 113

Gap between Investing and Vesting Expressive Resources ............................. 115

Socializing with Friends and Social Capital.................................................... 117

Life Satisfaction and Social Capital ............................................................ 119

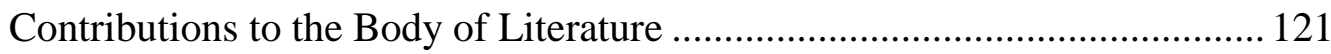

Perceived Expressive Resources .................................................................. 122

Implication of the Current Study to International Students............................... 123

Inconsistency of Communication Based Emotional Support Scales................ 125

Limitations and Future Prospects ............................................................... 127

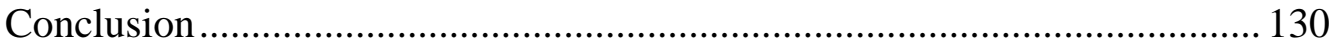

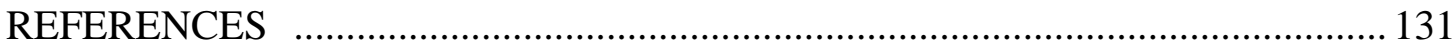

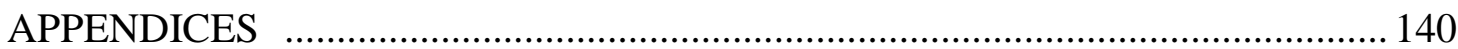

A. Approval of Human Subject Application …………………………...... 140

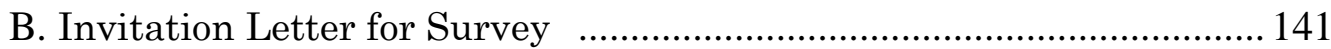

C. Reminder of the Survey …………………………............................... 143

D. Survey for Friendship of International Students ................................. 145 


\section{LIST OF TABLES}

Table 1: Participants’ Countries of Origins.

69

Table 2: Number of Housemates .......................................................................... 72

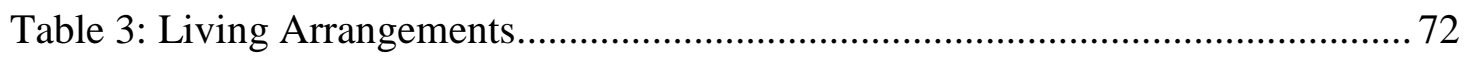

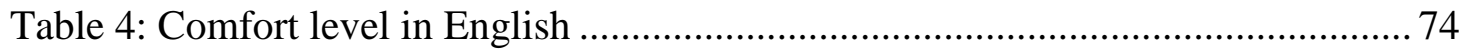

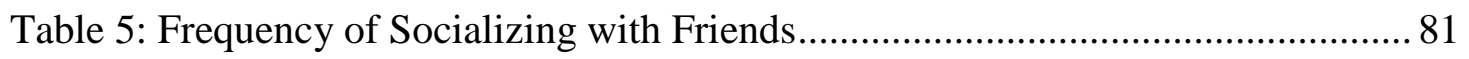

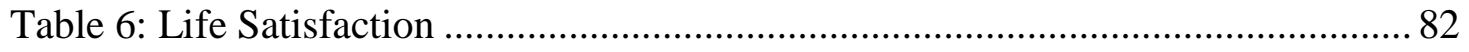

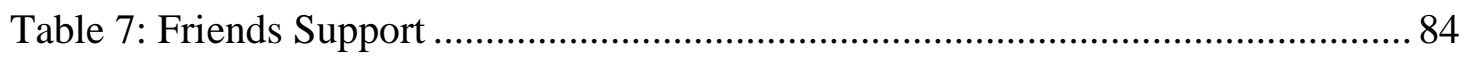

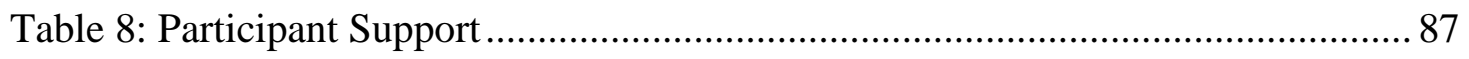

Table 9: Socializing with Friends Independent Sample t-tests ................................ 92

Table 10: Friends Support Independent Sample t-tests ........................................ 93

Table 11: Predictors of Friends Support............................................................... 95

Table 12: Participant Support Independent Sample t-tests..................................... 98

Table 13: Predictors of Participant Support .......................................................... 99 
Table 14: Life Satisfaction Independent Sample t-tests ..... 101

Table 15: Predictors of Life Satisfaction (1) 103

Table 16: Predictors of Life Satisfaction (2) 104

Table 17: Paired Samples t-test: Participant and Friends Support by Country of Origin 108 


\section{LIST OF FIGURES}

Figure 1: Pearson Correlations between Variables ................................................. 110 


\section{PREFACE}

During my graduate coursework, I interviewed a Japanese friend. She lost her

American husband rather abruptly several years prior to the interview. A middle aged full-time housewife with very limited English skills (her husband spoke Japanese), she was unexpectedly forced to raise three children alone. During the interview, I found that a support network of her friends, her deceased husband's friends and coworkers, children’s friends' mothers, and neighbors had been helping her and her children.

They helped her through selling and downsizing the house, dealing with government paperwork, providing a job for her, etc. Meanwhile, she had been helping her friends, too. For example, when one of her friends was diagnosed with cancer, she and others took turns cooking for the friend and her family over the course of several months. She also baby-sat and dog-sat frequently for her friends and neighbors. She lived in a reciprocal circle of friendship and mutual help.

This interview inspired me to think about friendship and social networks as a social device for survival. It guided me to social capital theory which considers social relationships as assets for individuals and communities. 
As an immigrant, I am curious how people survive in a new environment. I am thrilled that my academic inquiry and personal quest meet each other in my Master's thesis. 


\section{Chapter 1}

\section{LITERATURE REVIEW}

Considering personal relationships to be assets is not innovative or novel, but this conventional "street wisdom" is the core idea of social capital. Yet in academic circles, the idea of examining relationships from this perspective received only minor attention until Bourdieu (1986) and Coleman (1990) started to develop the theory about two decades ago. Social capital has recently become a popular term, but the conceptualizations (meanings) and operationalizations (measurements) of the term tend to vary depending on which element of the concept is being emphasized.

In this chapter, I will discuss how the concept of social capital has been developed in the communication discipline and other fields. I start with the historical unfolding of the theory and recent popularizations of the term. After explaining how scholars categorized the concept, I will shift to a discussion of how the concept has been adapted to the communication field. I then add my working definition of social capital. 


\section{Social Capital: History of the Concept}

The term "social capital" can be traced to the beginning of the $20^{\text {th }}$ Century when Lyda Judson Hanifan, an educator in West Virginia, used the term in 1916 to stress that community cooperation is essential to operate a successful school (Putnam, 2000, p. 19). Hanifan defined social capital as "those tangible substances that count for most in the daily lives of people: namely goodwill, fellowship, sympathy, and social intercourse among the individuals and families who make up a social unit” (Hanifan, 1916, p. 130). The concept was revitalized years later by two sociologists, Pierre Bourdieu (1986) and James S. Coleman (1990).

Bourdieu and Coleman each developed distinct yet overlapping conceptualizations of social capital. Bourdieu (1986) focused on how an individual's social relationships (e.g., family, school, clubs, etc.) produce access to resources. Bourdieu reasoned that social capital is determined by two elements: "the size of the network of connections" available to the individual, and "the volume of the capital (economic, cultural or symbolic)" of each member within the network (p. 249). That is, Bourdieu emphasized the network and resources within the network. 
Coleman took a slightly different approach to social capital, linking individual action with self-interest. Coleman considered social capital the result of individuals' rational choices to achieve personal interests. As a result, he regarded social capital as both a compound of social relations (networks) and a consequence of social relations (including trust). Coleman focused on outcomes of social capital, noting "social capital is productive, making possible the achievement of certain ends that would not be attainable in its absence” (Coleman, 1990, p. 302).

\section{Social Capital Erosion in the United States}

While the sociology scholars had been refining and polishing social capital theory in their discipline, political scientist Robert D. Putnam popularized the term with the publication of his 2000 book, Bowling Alone. Viewing social capital as the linchpin to well-functioning, democratic and healthy communities, Putnam defined social capital as “connections among individual's—-social networks and the norms of reciprocity and trustworthiness that arise from them” (Putnam, 2000, p. 19).

According to Putnam, social capital in the United States has been drastically eroding for the last several decades, as individuals eschew community-based activities 
(such as bowling teams) for more individually oriented pursuits (such as surfing the Internet). By using national data such as the DDB Needham Life Style archive, the General Social Survey (GSS), and Roper surveys, Putnam (2000) asserted that social capital erosion can been seen in six areas in society: politics and public affairs, civic and social participation (community-based, church-based, and work-based voluntary associations), informal social connections, "willingness to help others” (altruism, volunteering, and philanthropy), social norms (reciprocity, honesty, and trust), and small groups (self-help organizations and book clubs). For example, political activities such as attending a public meeting and signing a petition have decreased since the 1960s. Involvement in religious groups and community organizations also declined, and the number of memberships in clubs such as bowling clubs and the Boy Scouts has dropped in the last several decades while crime rates have jumped. Putnam concluded that such declines indicated the erosion of social capital. Although he did not test causal relationships, Putnam conjectured that social capital erosion is caused by multiple social elements. The biggest is the demographic shift of the baby boomers as the largest cohort: the first generation raised with television. Currently, baby boomers work longer hours, more women work outside the home, communities are 
sprawling to suburbia, and people spend more time watching television (Putnam,

1995a; 1995b; 2000). In short, Putnam asserted that people have become so busy working, commuting, and watching television that they do not have enough time and energy to unite with other people and engage with their communities.

Putnam's work has advanced social capital as a multidimensional construct with influences on societal, communal, and individual levels. In turn, his work has generated empirical studies that employ a variety of methods to measure social capital. At present, the concept of social capital has been used in various disciplines including but not limited to education, sociology, psychology, political science, economic, public health, business, and communication.

\section{Categorization of Social Capital}

Before discussing the explication and operationalization of social capital in the communication discipline, I will outline several categorizations of social capital. The concept of social capital includes many sub-concepts and has been developed in various academic fields. Therefore, scholars take different approaches when categorizing the concept. I will discuss the individual-collective level of social capital, 
bonding and bridging social capital, network-participatory capital, and

instrumental-expressive social capital. Online-offline social capital categorization,

however, will be discussed in the communication section.

\section{Individual and Collective Levels of Social Capital}

In their discussion of "social reality,” Jack McLeod and Steven Chaffee pointed out that there are two kinds of social reality: social reality and social reality (1972). Social reality (Sr) examines an individual's cognitive system in a social situation. In contrast, social reality (sR) focuses on a social system level that is the "actual degree of agreement or consensus among the members of that system” (p. 52). The concept of social reality varies depending on which word—social or reality—is emphasized. As a result, different scholars focus on different concepts while using the same term.

Social capital research has an inherently similar problem, with multiple definitions that depend on which word is emphasized. Putnam suggested that social capital has two levels, an individual level and a collective level (2000, p. 20). The individual level of social capital may benefit oneself (e.g., finding a job) while the collective level of social capital influences society as a whole (e.g., improved public 
health and decreased crime rates). As a political scientist, Putnam emphasized the social system level of the social capital function (e.g., social capital erosion of U.S. society), while sociologists including Bourdieu (1986) and Lin (2001) focused more on the individual level of social capital. For example, Lin and Dumin (1986) examined how an individual found a job by using his or her social network; they found that knowing someone in a higher job prestige position was positively and significantly related to an individual's current job status.

\section{Bonding and Bridging Levels}

In addition to individual-community categorization of social capital, Putnam (2000) separated social capital into two levels: bonding and bridging. Bonding social capital typically refers to strong and close connections, that is, "inward looking and tend[ing] to reinforce exclusive identities and homogeneous groups” (Putnam, 2000, p. 22). According to Putnam, examples of bonding social capital include "ethnic fraternal organizations, church-based women’s reading groups, and fashionable country clubs” (p. 22). Such intimate relationships provide emotional support as well as substantive 
support such as "furnishing start-up financing, markets, and reliable labor for local entrepreneurs," to the individual (p. 22).

In contrast, bridging social capital is associated with weak and loose connections among people. Bridging social capital can be seen in the example of the civil rights movement and youth service groups. Bridging social capital is "outward looking” and “encompass[es] people across diverse social cleavages” (Putnam, 2000, p. 22). Bridging social capital may be shallow but wider in range than bonding social capital. People in these loose relationships often have different backgrounds, so bridging social capital may provide individuals with new resources or opportunities that the individual cannot meet within his or her bonding social capital (Williams, 2006). For example, when a high school student is choosing his university, his classmates may know as much as he does about colleges and universities because they are in a similar network (e.g., similar age, same school, same community, etc.). The student may receive information when he talks to his high school teachers and advisors, parents, advisors in universities, or friends who are already in universities. They can provide information which his classmates cannot, because they have dissimilar backgrounds from the student and his classmates. 
Putnam, however, does not explain why two kinds of connections exist in bridging and bonding. Why does an individual have a strong connection with someone and a weak tie with someone else? Putnam's bonding-bridging categorization describes the phenomenon but does not explain the mechanism. Furthermore, the categorization is often acknowledged in conceptualization, but often ignored in operationalization. Putnam himself stated that he found "no reliable, comprehensive, nationwide measures of social capital that neatly distinguish 'Bridgingness' and 'Bondingness'” (Putnam, 2000, pp. 23-24; see also Williams, 2006).

To summarize, the bonding and bridging categorization distinguishes social capital by the degree of strength (strong-weak) and openness (inclusive-exclusive) of the connection among individuals as well as similarity of the individuals. Bonding social capital increases strong and close ties among people within a homogeneous context while bridging social capital is a weak and loose link between individuals with dissimilar backgrounds. 


\section{Function of Social Capital}

Some scholars categorize the social capital level by its function. Wellman and Frank (2001) categorized social capital into two forms: network and participatory.

Network capital is generated from relationships with friends, neighbors, relatives, and colleagues who provide emotional and material aid, as well as companionship and sense of belonging. Participatory capital refers to involvement in civic, political, and community life. This categorization is unique in terms of distinguishing social capital by its function, and is beyond the scope of the current study.

\section{Instrumental and Expressive Actions in Social Capital}

Another categorization is rationalized by basic motivations for human behaviors.

Nan Lin (2001) defined social capital as "consisting of resources embedded in social relations and social structure, which can be mobilized when an actor wishes to increase the likelihood of success in a purposive action” (p. 24), and asserted that social capital induced two kinds of actions: expressive action and instrumental action. ${ }^{1}$

\footnotetext{
${ }^{1}$ Although Lin did not mention this in his book, I would argue that his distinction between instrumental action and expressive action are influenced by a German sociologist, Jürgen Habermas who distinguished action as two types; communicative action and instrumental action.
} 
From the sociological perspective, Lin explained that individuals have two main motives for taking action: maintaining existing resources and gaining additional resources. Maintaining is more important than gaining since an individual will be endangered by losing resources he or she already has. For example, people do not worry about getting a raise when they are worried about getting laid off. Individuals try to gain new resources when they can secure resources they already have (pp. 32, 46). In order to maintain resources, an individual needs "recognition by others of one’s legitimacy in claiming property rights to these resources or sharing one’s sentiments... There is no action required beyond this public recognition and acknowledgment of others” (p. 45). For example, when a woman talks with her friend about love for her boyfriend, or a child complains to his mother about a missing toy, speakers expect listeners to show empathy; acknowledging and exchanging feelings. In other words, individuals engage in “recognizing, legitimizing, and sharing ego's claims to their resources” (p. 46). Such expressive actions are more likely to occur among individuals who share similar traits and backgrounds because an individual has a greater chance to capture the expected return from others who are alike. If others have very different characteristics and lifestyles, an individual may not be able to expect a "normative 
match between effort and return” (p. 59). For expressive action, communication conveys one's feeling, but also communication itself is a goal of the action. Expressive action does not gain additional resources, but prevents potential resource loss (Lin, 2001, p. 244).

Lin also notes there are three kinds of return for expressive actions: physical health, mental health, and life satisfaction. Lin did not explain life satisfaction in detail, but stated that it is indicated by "optimism and satisfaction with various life domains such as family, marriage, work, and community and neighborhood environment” (2001, pp. 244-245).

When their resources are secured, individuals try to gain additional resources. In this case, communication is a way to "trigger actions and reactions from others leading to more allocation of resources” (p. 46). This kind of behavior is called instrumental action. People within similar environments or social positions are more likely to have similar resources. In order to obtain a new resource, individuals are more likely to approach others who are different from themselves. Therefore, instrumental actions are more likely to take place between individuals with different backgrounds. An example of an instrumental action includes looking for a job or job references, 
borrowing items (e.g., car, book, summer house, etc.), and getting useful information or services.

Similar to Lin’s approach, Yuan and Gay (2006) classified social networks as instrumental networks and expressive networks. Instrumental network ties are used to exchange information, advice, and resources in order to achieve tasks whereas expressive ties ("affective ties," in other words) generate positive and negative emotions (p. 1063).

The expressive-instrumental categorization appears to be similar to the bonding-bridging categorization. Both categorizations include emotional support from strong connections among homogeneous relationships and substantial (instrumental) resources from weak and loose connections among people from different backgrounds. However, expressive-instrument categorization explains why two kinds of social capital are produced, while the bonding-bridging categorization only explains the phenomenon but not the mechanism of the process. 


\section{Social Capital Research in the Communication Discipline}

As I stated earlier, social capital became a popular subject to study among communication scholars as well. In this section, I will discuss the explications and operationalizations of the term in our field.

Social capital research in the communication discipline can be categorized in three ways. First, mass and political communication scholars have examined media influences on social capital. Second, in recent years, scholars have started to focus on computer-mediated communication and online social capital. Third, social capital is also explored in its relationship to promoting well-being in health communication. For

example, Thorson and Beaudoin (2004) examined how a public health media campaign influenced youth’s “health social capital” including awareness, attitudes, and behaviors related to health.

Each trend has a different research approach with slightly different explications and operationalizations. In the following sections, I will discuss media influence on social capital and online social capital in more detail, leaving health communication to another time. 


\section{Media influence on Social Capital and Refutations to Putnam's Arguments}

Social capital research in the communication field started as a refutation to

Putnam's assertion that social capital is eroded by television viewing. Putnam insisted that one of the main causes of declining social capital is due to television viewing for two reasons. One is a "time displacement” reason, that people spend more of their leisure time watching TV so they do not have time to socialize with others. "TV watching comes at the expense of nearly every social activity outside the home, especially social gatherings and informal conversations” (Putnam, 1995b, pp. 678-679). The other reason is the "mean world effect” postulated by George Gerbner and colleagues. That is, heavy viewers of TV tend to perceive the world more pessimistically and skeptically (Putnam, 1995a, 1995b, 2000).

Many communication scholars, especially in mass communication and political communication, disagreed with Putnam’s simplified analysis and lack of empirical data to support his claims. They were quite skeptical toward Putnam’s idea of considering the media effects by measuring how much people watch television instead of attendance and engagement with TV viewing (Shah, 1998; see also Moy, Scheufele, \& Holbert, 1999; Scheufele \& Shah, 2000; Shah, McLeod, Yoon, 2001; Shah, 
Schmierbach, Hawkins, Espino, \& Donavan, 2002; Shah, Cho, Eveland, \& Kwak, 2005). "These simplistic critiques of the media are grounded on the assumption that there is one mass communication experience (rather than multiple motives and uses) and one audience (rather than different types of users)” (Shah, McLeod, et al., 2001, p. 465).

Since the concept of social capital has developed in multiple disciplines and includes various sub-terms, there is no unified explication of the term. For example, Shah defined social capital as "the resources of information, norms, and social relations embedded in communities that enable people to coordinate collective action and to achieve common goals” (Shah, McLeod, et al., 2001, p. 467). Moy, Scheufele and Holbert regard social capital at an individual level as civic engagement (1999, p. 30) whereas Zhang and Chia (2006) write that civic and political engagement is not part of but a consequence of social capital, regarding social capital as "latent and potential resources for participation” and defined by social connectedness and trust (pp. 281-282).

Although measurements of social capital hold several operational problems, such as vague wording and non-exhaustive questionnaire wording, a number of research 
studies vindicate TV viewing as the cause of social capital erosion (Kikuchi \& Coleman, 2008). Findings consistently indicate that the amount of TV viewing does not correlate with a decrease of social or interpersonal trust (Lee, Cappella, \& Southwell, 2003) or social capital (Beaudoin \& Thorson, 2006). Rather, watching television (hard news) had a small and indirect but positive influence on civic participation (Shah et al., 2005). However, the relationship between entertainment TV viewing and social capital varies depending on the study. Watching science fiction (Shah, 1998) and situation comedies and reality TV shows are negatively related to civic participation (Shah, McLeod, et al., 2001). Fleming, Thorson and Peng (2005) found that entertainment TV viewing (including "situation comedies, action shows, daytime soap operas, movies on television, talk shows, sports, music videos, game shows, and cartoons,” p. 227) had a negative influence on volunteering and interpersonal communication. In contrast, watching social dramas was positively related to civic participation (Shah, 1998; Shah, McLeod, et al.,). Shah and colleagues concluded that "the relationships between the use of television, civic engagement, and interpersonal trust must be viewed as more conditional—highly dependent on the type 
of programming" and "how much television people watch appears to be less important than what they are watching” (Shah, 1998, p. 490).

In the effort to refute Putnam, some scholars also examined the effect of the Internet on social capital. For example, Shah and his colleagues believe the Internet has a positive influence on civic engagement since the Internet enables individuals to increase their knowledge and to establish connections among individuals and help them organize their actions (Shah, Kwak, \& Holbert, 2001). Findings suggest Internet usage in general does not have an effect on trust or sociability (Uslaner, 2004), but certain kinds of Internet use (e.g., gathering information and exchanging ideas) have positive effects on civic engagement, which is an indicator of social capital (Shah, Cho, Eveland, \& Kwak, 2005; Shah, McLeod, \& Yoon, 2001; Shah, Kwak, \& Holbert, 2001). Also, the size of the social support network for a heavy Internet user is actually larger than other Internet users (Uslaner, 2004).

A noteworthy point is that although these researchers examined Internet influence, the focus of their examination was the impact on offline social capital (e.g., volunteer work). They were less concerned with social capital created and exchanged 
online. In other words, for these studies, the Internet is not a new virtual arena where social capital exists, but just a new medium.

Such studies share similar research methodologies with Putnam’s. First, many studies conducted a secondary data analysis of national surveys (Shah, 1998; Shah, Kwak, \& Holbert, 2001; Shah, McLeod, \& Yoon, 2001; Uslaner, 2004). Some conducted large scale telephone surveys which asked similar questions as the national surveys (Moy, Scheufele, \& Holbert, 1999; Zhang \& Chia, 2006). Second, many scholars pay close attention to the relationship between social capital and the regional community where the participants live (Beaudoin \& Thorson, 2006; Beaudoin, 2007; Moy, Scheufele, \& Holbert, 1999; Zhang \& Chia, 2006). Participants were asked how often they interacted with people who live within or outside of their residential neighborhood, community or city, but ignored other communities, such as schools or work places. Third, civic participation or engagement, such as working as a volunteer or attending a neighborhood meeting, are considered important elements of social capital (Lowrey, 2004; Moy, Scheufele, \& Holbert, 1999; Scheufele \& Shah, 2000; Shah, Kwak \& Holbert, 2001; Shah, McLeod \& Yoon, 2001; Shah, Schmierbach, Hawkins, Espino, \& Donavan, 2002; Zhang \& Chia, 2006). To summarize, 
communication studies have focused on social capital at the individual level within or outside of the residential area and on the relationship between social capital and civic participation.

\section{Social Capital Research in Online Communication}

Social capital has been categorized by various dimensions, such as

bridging-bonding and individual-collective. Communication scholars also classify the concept by which communication medium is used and where it exists, either offline and online. Offline social capital refers to social capital in the traditional, face-to-face communication, sometimes including telephone calls. In contrast, online social capital is generated via computer mediated communication (CMC) such as using e-mail, chat, webcam, and instant messaging. At present, online communication cannot be ignored or overlooked in research since such communication is becoming more common and essential in our daily lives. Meanwhile, online and offline communication are often interwoven and difficult to distinguish one from another. Aubrey, Rill and Chattopadhyay (2008) argue that college students may have difficulty picturing their 
friendship without CMC since "online and offline communities are highly inter-connected.”

Research about online social capital has a different research paradigm from the other cluster of studies that refute Putnam's argument. Some of the counterargument studies measured Internet use's influence on social capital (Shah, Cho, Eveland, \& Kwak, 2005; Shah, Kwak, \& Holbert, 2001; Shah, McLeod, \& Yoon, 2001; Uslaner, 2004). However, these studies focused on Internet influence on an offline community; online social capital was out of their scope. In an online social capital study, the physical community to which participants belong gets little attention. Even when social capital in a physical world ("offline” social capital) is measured, the residential community is often ignored. Instead, most studies measured communities and networks where participants functionally or emotionally belonged, such as a university community (Aubrey, Rill \& Chattopadhyay, 2008; Ellison, Steinfield, \& Lampe, 2007; Williams, 2006, 2007; Yuan \& Gay, 2006). Most importantly, these online social capital studies do measure social capital created in an online virtual world, which is often overlooked. For example, Ley (2007) observed communication among members of a pregnancy and mothering support group, which existed solely online. 
Williams (2006) argued that the Internet should not be treated as an extension of television because of the differences in how people use these two media. "TV viewers do not typically take an active role in communicating with other viewers through the television, while Internet users do take an active role in communicating with other users” (p. 596). In other words, TV is a one-way medium while Internet is interactive. Since these online social capital studies treat the Internet differently from the studies refuting Putnam's work, their research takes different approaches to conceptualizing and measuring social capital. For example, bonding-bridging social capital categorization is not used in research refuting Putnam, but used very often in online social capital research (Aubrey, Rill \& Chattopadhyay, 2008; Williams, 2006, 2007; Yuan \& Gay, 2006). Considering social capital as a cyclical process of network building and social capital generating, Williams (2006, 2007) employed bridging and bonding categorization. Williams considered bridging social capital as a weak and shallow but wider and inclusive relationship which occurs among people with different backgrounds; therefore, bridging social capital may not provide emotional support but may "broaden social horizons or world views, or open up opportunities for information or new resources” (Williams, 2007, p. 399). Bonding, on the other hand, 
provides emotional support as well as substantial help (e.g. offering a loan) since it derives from tightly connected relationships (e.g., family and close friends). Williams (2006) created the Internet Social Capital Scales which measure four dimensions of social capital between online-offline contexts and bonding-bridging. Williams (2007) examined these four dimensions of an Internet user by conducting a web survey, and found that participants have "significantly more bonding social capital offline” but also “significantly more bridging social capital online” (p. 401). This study implies that Internet usage may decrease offline social capital; instead, the usage may create social capital online.

To summarize, communication scholars who examine online social capital take a different approach from those who examine media influence on social capital and refute Putnam. Online social capital research considers the Internet’s virtual world another realm and treats it separately from the face-to-face, offline world. These communication scholars often employ the bonding-bridging categorization to measure different types of social capital. Even when measuring an offline world, scholars are still measuring a realm participants are emotionally connected to, such as a circle of friends. 


\section{Social Capital Explication}

Steven H. Chaffee (1991) emphasized the importance of concept explication or conceptualization. Conceptualization systematizes and elucidates "what we observe” (p. 1), and connects the target of observation with theories. Concept explication enables reinforcement of the connection between theory, observation, and research. He asserted that concept explication is especially important in communication research, since communication scholars must study variables that often cannot be directly observed.

Concept explication also enhances validity and reliability of research. "Only if there is a clear conceptual definition of what we wish to know about, can we access the validity of the answers elicited by any method” (p. 13).

Concept explication is not the same with other types of definitions; the purpose of explication is to connect proofs with meanings and words in every research step and remove unrelated meaning from a term and to reveal possible meanings (p. 72). Explication also attempts to focus on one definition within the research. To summarize, explication is the continuing process of polishing and refining meaning, and improving the precision of the concept. 
The next sections examine how communication researchers conceptualize social capital vis-à-vis concept explication.

\section{Social Capital as Communicative Process}

Lin (2001) defined social capital as "resources accessible through social ties that occupy strategic network locations and/or significant organization positions” and defined it operationally as the "resources embedded in a social network accessed and used by actors for actions” (pp. 24-25). In other words, individuals have to take actions in order to access resources embedded in other people within the network. In that case, such action always takes place between an individual and others; that is, actions in the social capital process should be considered as communication. When an individual intends to activate his or her social capital (use resources that others have), the individual has to communicate with the person who has the resource. For example, when an individual wants to use a car which his friend owns, he needs to communicate (e.g., ask, demand, persuade, barter, lie, etc.) with the owner of the car.

Social capital cannot be processed without communication between individuals.

Nevertheless, the communicative aspects of the social capital process in research have 
received little attention. The current study emphasizes the importance of communication in social capital, and centers communicative action in the social capital process.

\section{Social Capital as Neo Capital Theory}

Pierre Bourdieu (1986) and James S. Coleman (1990) developed social capital in a sequence of other capital, such as human capital and cultural capital. Human capital refers to accumulated resources within an individual such as skills and capabilities that an individual can freely use or discard (Coleman, 1990; Lin, 2001). Cultural capital also represents resources, such as skills, values and knowledge, but the focus is that these resources are generated, imposed and influenced from social structures to an individual (e.g., parents teach family values to their children) (Bourdieu, 1986). Social capital, in that sense, signifies resources invested in social relations (Lin, 2001). However, as the term became popular, the "capital” aspect of the concept seems forgotten. In defining social capital as "connections among individuals—social networks and the norms of reciprocity and trustworthiness that arise from them," Putnam valued the importance of social networks but neglected the "capital" element 
of the term (2000, p. 19). Similarly, most communication scholars pay little attention

to the capital aspect of the concept. For example, Moy, Scheufele and Holbert noted

Marx’s classic capital theory but did not examine the relationship between classic

capital and social capital; rather, they regarded social capital in the same light as

“social connectedness” (1999, p. 29).

Lin (2001) considered capital as "investment of resources with expected returns”

(p. 3). He stated that social capital, a part of neo capital theory, has two components:

an individual invests in other people within his or her networks and relationships, and an individual vests return by mobilizing or capturing resources that are embedded in others within his or her networks and relationships. Along with his assertion, the current study perceives social capital as a part of neo capital theory and emphasizes the process of "investing and vesting."

\section{Definition of Social Capital in the Current Study}

While reviewing the literature, I realized that most communication research

simply employed the definitions from the past, originating from the fields of sociology

and political science. I argue that, as communication scholars, we need to develop our 
own definition of social capital, since Putnam and others do not focus on the communication aspects of the social capital process. Social capital is a "dynamic" process (Coleman, 1990, p. 302) to be “mobilized” (Lin, 2001, p. 24), and such mobilization cannot be done without communicating with others in the networks. In other words, communication is the "engine” of the process.

The process is also cyclical. An individual communicates with others within his or her social network for a desired outcome, and the process continues to enhance and reinforce the social network. Similar with Marx’s capital theory and neo-capital theories, social capital (resources) is both invested and vested (Lin, 2001).

To summarize, I define social capital as: “a communicative process whereby an individual invests and vests resources embedded in others within his or her social network to increase the likelihood of success for purposive action.”

In this definition, resources can be either material (e.g., property), symbolic goods (e.g., wealth and power), or social networks (Lin, 2001, p. 43). 


\section{Social Relationships in Social Capital}

Although the explication of the term social capital varies in the literature, a common feature that links studies of social capital is relationships with others: a tie or link among individuals within a community, such as neighbors, acquaintances and friends. Since social capital thrives only in relationships among individuals, social relationships are an essential component of social capital. The nomenclature varies somewhat, with researchers referring to "social networks" (Beaudoin \& Thorson, 2006; Putnam, 2000), “social connectedness” (Zhang \& Chia, 2006), and “social relations” (Beaudoin, 2007; Coleman, 1990; Shah, McLeod, et al., 2001).

Social relationships are measured in a multitude of ways: The size of the social support network (Usulaner, 2004), public attendance (Shah et al., 2002), social connectedness (Zhang \& Chia, 2006), neighborliness (Beaudoin \& Thorson, 2004, 2006), social support (Beaudoin \& Thorson, 2007), civic participation (Lowrey, 2004;

Scheufele \& Shah, 2000; Shah et al., 2002; Shah, Kwak, et al., 2001; Shah, McLeod, et al,. 2001), and association membership (Beaudoin \& Thorson, 2004, 2006; Fleming, Thorson, \& Peng, 2005; Putman, 2000). These measurements can be categorized along two dimensions: informal-formal and static-dynamic, yet scholars pay little attention 
to these categorical differences (Kikuchi \& Coleman, 2008). For example, "association membership” measures what kind of clubs and organizations (e.g., a book club or a neighborhood association) an individual associates with, while "social connectedness" measures the frequency an individual would "spend an evening socializing with others” (Zhang \& Chia, 2006, p. 286). I argue being a member of a club is a more "static" condition than spending an evening simply socializing with others. Also, membership in such clubs is more formal (e.g., commitment and preparation) than socializing with neighbors. Since the current study focuses on the communicative dimension of the social capital process, concrete social interaction among individuals is important; and measuring informal and dynamic behaviors reflects actual interactions between people more accurately than measuring formal and static conditions. Having a membership of a book club does not always guarantee the concrete interaction with people whereas "spending an evening” cannot be realized without talking, communicating, interacting with people. For the current study, I will measure "social relationships" by such informal social interactions. 


\section{Life Satisfaction and Social Capital}

Another important component of social capital research is "life satisfaction.”

Although most definitions of social capital do not include life satisfaction, the concept is often measured in the research. Life satisfaction is often treated as a dependent variable of social capital; that is, life satisfaction is the outcome of social capital (Ellison, Steinfield, \& Lampe, 2007; Scheufele \& Shah, 2000).

In their study about social capital and Facebook usage among college students, Ellison, Steinfield, and Lampe (2007) measured life satisfaction by employing the Satisfaction With Life Scale (SWLS), originated by Ed Diener and colleagues (Diener, Emmons, Larsen \& Griffin, 1985). They found that life satisfaction at college is correlated with both bonding and bridging social capital. In the second analysis of the national survey data from DDB Needham’s 1997 Life Style Study, Scheufele and Shah (2000) examined life satisfaction and found that it had a significant and positive correlation with social trust and civic engagement (p. 121).

Life satisfaction is also treated as an independent variable to predict social capital (Shah, Schmierbach, Hawkins, Espino, \& Donavan, 2002) or as a part of social capital (Shah, McLeod, \& Yoon, 2001). I acknowledge that the relationship between 
social capital and life satisfaction can be cyclical and interrelated. Having a higher

degree of social capital (e.g., rich interactions with many friends) probably contributes

to a higher degree of life satisfaction. Meanwhile, having a higher life satisfaction may

have some influence on an individual to increase their social capital, but its impact

may be weaker compared to the effect of social capital on life satisfaction. People can

be satisfied by many causes, and some of them can have a higher life satisfaction

without having a rich friendship or network as long as their other needs (e.g., money

and power) are fulfilled. Therefore, in order to get a snapshot of the mechanism, the

current study will treat life satisfaction as a dependent variable that is the outcome of

social capital.

\section{Is Trust Part of Social Capital?}

Many scholars include other components, such as social norms and trust in their definitions of social capital. Social trust is considered as "the lubricant of the inevitable frictions of social life” (Putnam, 2000, P. 135) whereas interpersonal trust is a “critical component of social capital” (Beaudoin, 2008, p. 551). 
Trust is an essential aspect to building social capital, especially on a collective level. Community members will not mobilize their resources with others when they cannot trust each other, especially in long term relationships (Ikeda, 2002).

Lin (2001) argued that culture, trust, and norms must be distinguished from social capital since they are "collective assets and goods" whereas social capital includes "relational assets" (p. 26). He acknowledged that such collective assets and social capital may have a causal relationship; trust nurtures relationships and the mobilizing of resources, or the other way around. However, these assets are not part of social capital. The current study, therefore, excludes norms and trust from the definition of social capital.

\section{Reciprocity: Unilateral Acts of Giving}

Putnam defined social capital as “connections among individual’s—social networks and the norms of reciprocity and trustworthiness that arise from them" (Putnam, 2000, p. 19). Sense of reciprocity is an essential aspect of creating social capital, although I do not include it in my definition. I agree with Lin's assertion that 
collective assets are not part of social capital (2001). However, similar to trust, reciprocity is an essential aspect to understanding the social capital mechanism.

The concept of reciprocity has been studied in social psychology and sociology. Sociologist Linda D. Molm (2010) examined the structure of reciprocity and found that when people take actions in reciprocal exchange, the benefit flows unilaterally. That is, "actors perform individual acts that benefit another, like giving help or advice, without negotiation and without knowing whether or when the other will reciprocate” (Molm, 2010, pp. 119-120). In this sense, reciprocity is different from a simple exchange behavior which is a joint action that two-parties negotiate and agree to for bilateral benefit whether the benefit is equal or unequal. In some cases of reciprocal behavior, benefits can be indirect and more diffused; "one actor gives benefits to another, and received benefits from another, but not from the same actor" (p. 122). Molm and her colleagues found individuals who experienced reciprocal forms of exchange feel strong "bonds of trust and solidarity" with others, even when there is no close personal relationship (p.126). To summarize, reciprocal action is not a negotiated exchanging behavior expecting to get a direct benefit return; rather unilateral acts of giving that may be rewarded directly or indirectly. By promoting 
bonds of trust and solidarity, reciprocal behavior greatly contributes to creating social capital.

\section{The Importance of Expressive Action}

Lin's (2001) definition of social capital promotes two kinds of actions:

expressive and instrumental. The current study focuses on expressive

action—particularly investing and vesting behaviors.

There are several reasons why expressive action should be explored in social

capital research. First, expressive action is often overlooked. Even though social

capital promotes two kinds of action, instrumental and expressive, many studies focus

on instrumental aspects of social capital (e.g., civic participation). Second, expressive

action leads to emotional support. Emotional support is defined as "expressions of

concern, compassion, sympathy, and esteem for another individual” (Weber \&

Patterson, 1996, p. 69). I argue that emotional support is the outcome of expressive

action in social capital. Such support is important for psychological well being and

maintaining life quality. Third, while the need for instrumental action can be replaced

by other capital such as money or products, the need for expressive action (i.e., 
emotional support) is not replaceable. Money can provide resources such as cars, computers, and information, but can hardly provide emotional support. Fourth, needs and goals of expressive action are common desires, while those for instrumental action can vary depending on the individual. In addition, it is very difficult to accurately measure instrumental action since it will range from borrowing sugar to getting a job reference. Also, instrumental actions cannot be studied without examining what social networks and the quantity of resources individuals hold (Lin, 2001). In other words, amounts and types of resources or power of positions vary depending on the social structure (e.g., an organization and a company) and such differences need to be considered during research.

\section{Conclusion}

Overall, social capital considers social relationships as assets. Although the definitions and operationalizations of social capital vary depending on the disciplines and on what scholars emphasize, the current study will focus on the importance of the communicative aspect of the social capital process. The social capital process includes the nature of "capital” which induces "investing" and "vesting” behaviors. By defining 
social capital as "a communicative process whereby an individual invests and vests resources embedded in others within his or her social network to increase the

likelihood of success for purposive action," the current study focuses on expressive resources, which will be interpreted as emotional support in the research. 


\section{Chapter 2}

\section{INTERNATIONAL STUDENTS OVERVIEW}

The target population of the current study is international students at Portland

State University. ${ }^{2}$ The current study chose international students as the target of the study for two reasons. Starting a new life abroad, international students initially have less complex social capital. Also, social capital is a requisite for international students trying to adapt and survive in a new environment.

As a student from Japan, I experienced the process of creating new social capital in a foreign environment, and I have seen many international students overcome difficult situations with the help of their friends. I have observed and experienced a strong solidarity and dense friendship among international students (and with American students as well). Many of my friends are international students and we all share a strong rapport. I also respect international students who are studying in a

2 Portland State University is a public state university located in downtown Portland, Oregon, United States. Enrollment in 2009 was 27,972 (21,674 undergraduate and 6,298 graduate students). 
foreign country in a non-native language. My personal experiences as a foreign student guided and grounded me in conducting this research.

Before moving on to the methodology of the study, I will present in an overview regarding international students.

\section{New social capital in the U.S.}

International students are generally detached from their existing social capital because they are physically distant from family and friends. Some students may be able to keep in touch via internet and telephone, but in general they have somewhat limited access to former avenues of social capital. As a result, it is likely that international students are prompted to establish new social networks and hence create new avenues of social capital.

In their Facebook study, Ellison, Steinfield and Lampe (2007) argued that "Social networks change over time as relationships are formed or abandoned. Particularly significant changes in social networks may affect one's social capital, as when a person moves from the geographic location in which their network was formed 
and thus loses access to those social resources ” (p. 6). For international students, such significant change occurs across country and culture.

Social capital is a continuous process. Relationships and networks with friends, family, coworkers, and neighbors are often interconnected and develop complexity over time. For example, when an individual lives in the same city for a long time, friends may become coworkers or coworkers may become roommates. Most American students have an outside-of-campus life, and friendship at a university might be influenced by conditions outside campus. Therefore, it is not easy to tease out the campus portion of the social capital process among students. Because international students may be relatively new to the environment (in this case, Portland State University), I assume that their social capital is less complicated than American students' and more concentrated within a campus-based network.

\section{Common Issues among International Students}

Obviously international students are not a homogeneous group; they have different cultural and ethnic backgrounds, different language skills, different reasons for studying abroad, and differ in how many years they attend Portland State 
University. However, they face common issues in addition to being distanced from their former social capital (i.e., family and friends in their home country).

Because they are new to the United States, they experience cultural differences and need to learn a new culture and way of living. In the university, they must adopt American learning styles such as in-class discussions and group work. Even though this can be enjoyable, such adaptation to a new culture and environment is an additional burden.

International students also face communication problems including language barriers. Although some students speak English as their native tongue, many international students have to face the challenge of learning new vocabulary and English composition while they are studying their own major. Even native speakers may need to accustom themselves to an American accent or American expressions.

These students also face the pressure of academic achievement. In order to maintain their visa status at PSU, international students are required to be full-time students every term (except students who are working on their thesis or dissertation), and must maintain good grades. If they fail classes, they may not be able to stay in the U.S. “Academic stress may pose a particular problem for international students who 
have left support networks of friends and family behind to study abroad” (Mortenson, 2006, p.128).

Because of these issues, international students often suffer from "feelings of loneliness, depression, isolation and homesickness” (Maundeni, 2001, p. 254).

Current international students in the United States also face a new issue. Since the terrorist attack of September 11 in 2001, the number of international students, especially those from Middle Eastern countries, has decreased because of increased restrictions. Applying for a student visa takes a longer time, and the fee for a student visa has been increased. Students from developing countries (especially Islamic countries) reported often experiencing disrespectful treatment by the U.S. officials in their home countries. As a result, many foreign students chose to study in other countries such as Canada and Australia (Mueller, 2009).

The U.S. government also increased scrutiny of international students who already in the U.S. (Mueller, 2009). Such increased scrutiny resulted in the international student offices of universities spending their time to keep track of international students' records and comply with student visa rules, instead of helping students directly (Siringi \& Franey, 2008). 
Compared to students who chose other countries, current international students in the United States may be more determined and/or privileged in order to study here.

\section{Need for Social Capital}

Because being distanced from established networks and facing the challenges of entering new environments are difficult, establishing new social capital is key to international students' success.

Kao (2004) argued that there are three benefits to having social capital in an educational setting. Although their study focused on immigrant and minority students, I argue that their assertions also apply to international students. The primary benefit of social capital is mutual support among individuals through obligations and expectations. However, Kao asserted that immigrants and minority groups are "more alienated from the majority" and "have fewer possible individuals with whom to exchange obligations and expectations," although they may have expected obligations and mutual reciprocity within their homogenous ethnic groups (immigrants from the same country) (2004, p. 172; see also Kao \& Rutherford, 2007). 
The second benefit of social capital is information channels. For greater student achievement, information gathering (e.g., about college and teachers) is essential. However, information gathering is not easy when an individual does not have social networks (Kao, 2004, p.173).

The third benefit is social norms. To be successful in an academic setting, students need to know how to behave appropriately. "Social norms not only provide rewards for positive behaviors, but exact sanctions for negative behavior.” (Kao, 2004, p.173).

These three benefits of social capital (mutual support, information exchange, and social norms) are essential components international students need to achieve for academic success.

In summary, since enrolling at Portland State University, international students have been separated from their established social capital in their home country and forced to establish social capital in their new environment. Social capital will provide various benefits for international students during cultural adaptation and academic pressures. Establishing new social capital will be very important for international students in order to survive college life. 


\section{Chapter 3}

\section{RESEARCH QUESTIONS}

\section{Research Questions}

My fundamental question in the study is: When an individual is physically separated from his or her original social capital and prompted to live in a new environment, how does the individual develop new social capital?

In the previous chapter, I defined social capital as “a communicative process whereby an individual invests and vests resources embedded in others within his or her social network to increase the likelihood of success for purposive action.”

In that sense, the question "How does an individual develop social capital?” can be divided into two parts: "How does an individual invest resources?” and "How does an individual vest resources?” Lin (2001) did not define either invest or vest, yet often re-phrased "vest” using other words such as “capture” (p. 21), "mobilize” and "access" (p. 29). To be consistent, I will use the term "vest" to refer to "capture, mobilize, access” and any action involving the resources embedded within others. I argue that 
“investing” in social capital should be considered "letting others vest resources or offer resources embedded within an individual” because both investing and vesting occurs among individuals. For example, when an individual uses a friend's car, the process is vesting for the individual but investing for the friend. A number of social capital studies focused on "what an individual does for others" such as volunteer and civic participation (investing), but few studies examined "what others do for an individual” (vesting). In order to explore the process of social capital, the current study examines both the investment and vestment part of the process.

Recall that Lin (2001) asserted that social capital promotes two kinds of actions: expressive actions and instrumental actions. The current study focuses on expressive action of social capital and leaves instrumental action for another time.

Expressive action takes place to protect and maintain an individual's resources from possible losses (Lin, 2001, p. 244). For example, when an individual worries about her job security, sickness of her dog, or depression, she worries that her resources will be lost. She takes expressive action to seek acknowledgement from and share sentiments with others. In other words, she needs to get emotional support from others. Lin did not explain further but I would argue that such acknowledgement and 
sentiment from others also should be considered a resource. For the study, I will call such resources expressive resources. Expressive resources are part of the resources an individual possesses, but they are distinguished from other resources that an individual feels are less secure (e.g., job). When an individual takes expressive action, the individual vests the expressive resources of other people (e.g., friends and family) in the form of getting emotional support from them. My first research question examines the "vesting" part of the social capital process. In particular, how individual vests his or her expressive resources.

Research Question 1: To what extent do international students vest expressive resources from new social capital?

Because social capital has two components, investing and vesting, the second research question explores the investing aspect of social capital. As I argued earlier in this section, "invest" could mean "letting others vest the resources of an individual" because in social capital, all investing and vesting takes place between individuals; when an individual vests, someone else is investing, and vice versa. In the case of 
expressive action, what an individual needs to invest is providing sympathy, empathy, acknowledgment and exchange of feelings (Lin, 2001, p. 46):

Research Question 2: To what extent do international students invest their expressive resources in new social capital?

The process of investing and vesting resources in social capital occurs at different times. Each process occurs separately, and there is no clear rule of investing and vesting. Since the social capital process is not a one-to-one correspondence in giving and taking, two actions may be taken separately.

Furthermore, in the social capital process, investing expressive resources may not result in vesting expressive resources, but other forms of resources such as items (e.g., loaning a car) or symbolic goods (e.g., fame and reputation). Since no literature was found focusing on the communicative process of investing and vesting expressive resources, it is difficult to predict the relationships between the two. Instead, an exploratory research question will be asked: 
Research Question 3: Is there a statistically significant relationship between the degree of investing and vesting expressive resources?

Social capital concerns resources embedded in someone else, so social capital cannot be discussed or examined without concerning the relationship between an individual and others.

Relationships with others have been measured in various ways, but I would argue that measuring dynamic and concrete behaviors will reflect the actual interaction among people more accurately (e.g., frequency of hanging out with neighbors), rather than measuring something static (e.g., years of residency). Therefore, the current study will ask individuals about actual interactions between international students and their friends. I am interested in how daily interactions among friends influence emotional support exchange (vesting and investing):

Research Question 4a: How does the contribution of social interaction with friends influence international students' vesting of expressive resources? 
Research Question 4b: How does the contribution of social interaction with friends influence international students' investing of expressive resources?

The research questions thus far focus on the process and mechanism of social capital, but not the outcome of social capital. Recall that Lin (2001) asserted three kinds of return for expressive actions: physical health, mental health, and life satisfaction. When an individual receives enough emotional support, his or her life satisfaction should increase. In other words, life satisfaction is an outcome of social capital. Because of the cyclical nature of the social capital process, it is hard to separate the cause from the result of the social capital process. Life satisfaction can influence social capital. However, to understand the mechanism and see the "snap shot" of the process, I will treat life satisfaction as an outcome of social capital:

Research question 5a: What is the contribution of vesting expressive resources on international students' life satisfaction? 
Getting emotional support can create life satisfaction, but I am also interested in the "investing" part of the process. Does an individual feel satisfaction by providing others "return of expressive actions" as well? I added another exploratory question:

Research question 5b: What is the contribution of investing expressive resources on international students’ life satisfaction? 


\section{Chapter 4}

\section{METHODOLOGY}

\section{Research Design Overview}

In order to collect the most reliable and valid data from a population of

international students at Portland State University, the current study was conducted by employing a survey. Babbie (2004) insisted that "survey research is probably the best method available to the social researcher who is interested in collecting original data for describing a population too large to observe directly” (p. 243). In other words, survey research enables me to examine international students and the type of support they exchange with their friends. Since my interest is to explore and grasp how expressive resources are invested and vested in the social capital process, I believe that survey research is the best way to examine my research questions.

To collect the data, an online survey instrument was used for several reasons.

First, participants of the study could easily access and participate in the survey. This allowed them to complete the study at their convenience. Second, a survey can be 
distributed to a large population easily and the researcher can expect quick responses from the participants and a better response rate. Third, an online survey can be a smaller financial outlay for the researcher.

WebSurveyor ${ }^{\circledR}$, a computer application for creating web-based surveys and collecting results, was used to develop the online survey. This software was chosen since Portland State University provided it to students free of charge.

The list of international students was provided by Juliette M. Stoering, a senior research analyst in the Office of Institutional Research and Planning (OIRP) at Portland State University. All students receive an official Portland State University email account from the Office of Information Technology (OIT), which distributed the survey to the students, thus keeping students’ private information confidential.

The survey was conducted for three weeks from February to early March in 2010. The first invitation letter was sent February 12 which is the sixth week of the winter term (see the Appendix B). The second letter was sent February 26. The content thanked students who already participated in the survey and reminded others to participate (see the Appendix C). The data collection ended on March 7, which is the ninth week of the term. 
All participants electronically signed a consent form before participating in the survey, as required by the Human Subjects Research Review Committee (HSRRC). Participant feedback was collected through the Websurveyor ${ }^{\circledR}$ application and analyzed by the Statistical Package for the Social Sciences (SPSS) program, version 17.0.

\section{Population of the Study: Participant Criteria}

The current study attempted to examine the investing and vesting of international students' expressive resources in the social capital process. Criteria qualifying someone as an international student were determined by visa status, not country of origin. Immigrants or naturalized citizens were not considered international students for the current study even though they were originally born and raised outside of the United States. Unlike international students, immigrants and naturalized citizens do not have to worry about passing a certain number of classes in order to maintain their student visa status. Also, they likely will be more familiar with American culture and academic traditions. In addition, they probably have already established richer social capital outside of the university. Immigrants and naturalized citizens were excluded 
from the current study because of these differences. Another criterion was that students had to be currently enrolled in Portland State University.

\section{Sampling}

According to the Office of Institutional Research and Planning (OIRP) website, 1,555 international students were enrolled at Portland State University by the fourth week of winter term 2010. Among these students, 1,025 were undergraduates (679 men and 346 women) and 530 were graduates (308 men and 222 women).

All international students with valid e-mail accounts $(n=1,526)$ were selected to participate in this study. Two e-mails (initial invitation and the reminder) were sent to all the international students who were enrolled in the winter term.

\section{Pilot Study: Feedback from Colleagues}

I conducted a pilot study when the survey instrument was developed. I sent the survey link to a group of my friends and colleagues who are not international students, and asked their opinions and feedback about the survey on January 20, 2010. Suggestions included changing some vague wording (e.g., "hung out with friends") 
and web design (e.g., text sizes). Although most of the corrections were rather minor, the suggestions improved the instrument.

\section{Survey Construction}

The survey instrument was approved by Human Subjects Research Review

Committee on February 1, 2010 (see the Appendix A). The survey instrument had five components: Communication Based Emotional Support (CBESS) from friends, CBESS from the participants to friends, socializing with friends, life satisfaction at Portland State University, and demographics. Except for demographics, all the questions were adapted from already established scales.

When the participants accessed the web survey, the informed consent page was displayed. Informed consent included the following: participation in the study was completely voluntary and they could stop participating anytime they wanted. They were informed that there was no direct benefit from taking the survey and were presented with an opportunity to win a \$25 gift card for the Portland State University bookstore. Participants were assured that all their information would be kept confidential, given contact information (for both Human Subject Research Review 
Committee and the researcher), and warned that there was a chance of becoming emotional or home sick by participating in this survey (see the Appendix D).

After participants acknowledged that they were giving informed consent, the survey began with the direction to picture their friends in their minds: "before you start answering the survey, please think about your friends at Portland State University (Let's call them your PSU friends).” Portland State University friends included any students the participant met at PSU (e.g., full-time, part-time, undergraduate, graduate, international, American, etc.).

Socializing with friends. The first set of questions asked how many times the participants socialized with their PSU friends over the last two weeks. These questions measured the frequency of different types of informal socializing in order to examine two research questions about how social interaction with friends influence "investing" and "vesting" of expressive resources (i.e., giving and receiving emotional support).

As I stated in the literature chapter, a common feature of social capital is social relationships. This is a tie or link among individuals within a community, such as neighbors, acquaintances and friends. Scholars measured this relationship in various 
ways. One common method asked participants about their informal socializing with others. For example, Zhang and Chia (2006) asked how often participants "spend an evening socializing with others,” and Moy, Scheufele, and Holbert (1999) asked about the frequency of "getting together with other people in their community." These questions attempt to measure actual, concrete behaviors of participants rather than the size of the social network (for further discussion, see Kikuchi \& Coleman, 2008).

In order to measure informal socializing, particularly among college students, I employed the measurement developed by Aubrey, Rill and Chattopadhyay (2008) for their Facebook study of college students. However, based on the feedback from the pilot study, I changed the wording of "hung out" to "engaged in other activities" and placed the item at the end of the list. Questions asked how many times the participants did the following activities with their PSU friends over the last two weeks. Answers were chosen from (1) never, (2) 1-3 times, (3) 4-6 times, (4) 7-9 times, (5) 10-12 times, and (6) more than 13 times. Items are as follows:

1. Studied with my PSU friends

2. Ate a meal with my PSU friends

3. Went to a restaurant or coffee shop with my PSU friends 
4. Went to a university-related event (e.g., sporting event, play) with my PSU friends

5. Watched TV with my PSU friends

6. Hosted a social gathering

7. Went to a party or a bar with my PSU friends

8. Engaged in other activities with my PSU friends

Emotional support from friends. The second set of questions used the Communication Based Emotional Support Scale (CBESS), which measured how friends provide emotional support to the participants. The scale was created by Weber and Patterson (1996). Based on other emotional support studies, they examined 20 items that were reworded with a communication focus. Using factor analysis, they selected 13 items that are internally reliable and unidimensional (p. 72). Rittenour and Martin (2008) proved the convergent validity of CBESS in their study with other support scales.

The Communication Based Emotional Support Scale was originally created to examine romantic relationships, but Rittenour and Martin (2008) changed its wording to reflect friendships and demonstrated that the scale can be used to measure 
emotional support among friends as well. For example, "When I tell my partner about a problem that I am having, he/she doesn't seem to be paying attention” was changed to “'when I tell my friend about a problem that I am having, he/she doesn’t seem to be paying attention” (p. 239). I extended this change to the plural form of friend. Since my scale was applied to international students who were not necessarily familiar with English or American expressions, some wordings were modified or simplified.

The Communication Based Emotional Support Scale 1 measures how friends provide emotional support to the participants, or how the participants receive their expressive resources (i.e., emotional support) from their friends. The scale is tied with the current study’s first Research Question: “To what extent do international students vest expressive resources from new social capital?” That is the "vesting” side of the social capital process.

Questions were answered on a 5-part Likert scale from (1) strongly disagree to (5) strongly agree. Items are as follow:

1. My PSU friends help me understand my thoughts and feelings about major life decisions (for example, career choice)

2. My PSU friends patiently and sensitively listen to me complain about a problem that I am having 
3. When I tell my PSU friends about a problem that I am having, they pay attention

4. My PSU friends help me deal with problems concerning other friends and/or family members

5. My PSU friends avoid me when I am upset (reversed)

6. My PSU friends are good listeners when I am upset

7. My PSU friends say and do supportive things for me when I am feeling down

8. When I want to talk to my PSU friends about what is bothering me, they seem to have something else to do (reversed)

9. My PSU friends show honest concern for my problems

10. My PSU friends give me good advice when I ask for it

11. My PSU friends make it very easy to discuss my personal feelings

12. My PSU friends listen to my side of the story even if they think that I am wrong

13. My PSU friends make an effort to make me feel better when I am depressed

Life satisfaction at Portland State University. The third set of questions

measured life satisfaction at Portland State University in order to examine research questions about the relationship between life satisfaction with giving and receiving 
emotional support. Recall that Lin (2001) asserted that there were three kinds of returns for expressive actions: physical health (i.e., maintaining physical condition), mental health (maintaining cognitive and emotional balance), and life satisfaction. Lin did not explain life satisfaction in detail, but stated that it is indicated by "optimism and satisfaction with various life domains such as family, marriage, work, and community and neighborhood environment” (pp. 244-245).

Ellison, Steinfield and Lampe (2007) measured "satisfaction with life" based on the Satisfaction With Life Scale (SWLS), which was developed by Ed Diener and colleagues (Diener, Emmons, Larsen \& Griffin, 1985). The scale consists of a 5-item instrument intend to measure "global cognitive judgments of one’s life” (Ellison, Steinfield, \& Lampe, 2007, p. 9). Ellison and her colleagues re-phrased the wording in order to fit in their school context. I employed their measurement and modified it to mesh with the Portland State University setting. This life satisfaction scale is related to one's campus life, not life in general. Life satisfaction in general may have more dimensions, such as financial condition or social status. The current study, however, only measured satisfaction at Portland State University. 
Questions were answered on a 5-part Likert scale from strongly disagree (1) to strongly agree (5). Items are as follows:

1. In most ways my life at Portland State University (PSU) is close to my ideal

2. The conditions of my life at PSU are excellent

3. I am satisfied with my life at PSU

4. So far I have gotten the important things I want at PSU

5. If I could re-live my time at PSU, I would not change anything

Emotional support from the participant to friends. The fourth set of questions was Communication Based Emotional Support Scale 2 (CBESS2). The items were the same as in CBESS1, but the subject was switched from "my PSU friends" to "I," which measured how the participants provide emotional support to their friends.

The Communication Based Emotional Support Scale 2 measures how participants provide their expressive resources (i.e., emotional support) to their friends. This scale indicates the "investing" side of the social capital process. 
Questions were answered on a 5-part Likert scale from strongly disagree (1) to strongly agree (5). Items are as follow:

1. I help my PSU friends understand their thoughts and feelings about major life decisions (e.g., career choice)

2. I patiently and sensitively listen to my PSU friends complain about a problem that they are having

3. When my PSU friends tell me about a problem that they are having, I pay attention

4. I help my PSU friends deal with problems concerning other friends and/or family members

5. I avoid my PSU friends when they are upset (reversed)

6. I am a good listener when my PSU friends are upset

7. I say and do supportive things for my PSU friends when they are feeling down

8. When my PSU friends want to talk to me about what is bothering them, I seem to have something else to do (reversed)

9. I show honest concern for my PSU friends' problems

10. I give my PSU friends good advice when they ask for it

11. I make it very easy to discuss my PSU friends' personal feelings 
12. I listen to my PSU friends' side of the story even if I think that they are wrong

13. I make an effort to make my PSU friends feel better when they are depressed

Demographics. The last section of the survey was about demographics. The survey asked the participants their gender, age (year of birth), length of residency at Portland State University (by asking which year and term they commenced their studies), and student status (undergraduate, graduate, or an ESL student). These questions were asked since I assumed the characteristics might have an influence on the social capital process.

Participants also answered questions about their accommodations: where they live (on-campus or off-campus), number of people living with them, and who these people are (e.g., roommate, family, or host family). These questions were asked because I assumed that where and who the participants live with would have an effect on how much the participants socialized with others.

Affluence was measured by four questions: if the participants owned a car or not, if the participants owned a computer or not, how much budget they had for cost of 
living, and how much they worried about their financial situation. These questions were added because the participants’ affluence might dictate their social capital. My assumption was participants who did not have other forms of capital (e.g., car or money) might rely more on friends, thus increasing their social exchange.

The survey also asked the participants’ English language familiarity: if they were native English speakers, their comfort level in English, and their English scores. In the social capital process, the participant has to communicate with others in order to utilize resources that others possess. Therefore, I assumed that English, one of the main communication tools, may be the key for the participants to access social capital. The survey ended by asking if the participants wanted to be a part of a random drawing as an incentive. The prize was Portland State University Bookstore gift certificate (\$25) for four randomly chosen participants. If they wished to participate, they were directed to a web page where they wrote their e-mail address. 


\section{Chapter 5}

\section{RESULTS}

This chapter will describe the results of the study, detailing responses to seven research questions in five categories: vesting expressive resources (receiving emotional support), investing expressive resource (providing emotional support), the relationship between vesting and investing expressive resources, influence of social interaction on social capital, and the relationship between social capital and life satisfaction. I will start by describing general findings of demographic characteristics and personal attributes. Then, I will discuss the results related to my research questions. At the end, I will include findings from a post hoc analysis.

\section{General Findings}

\section{Demographics}

The invitation for the web-based survey was sent via e-mail to 1,526

international students who enrolled the winter term 2010 at Portland State University. 
A total of 195 international students completed it. One participant refused to agree with the informed consent, so the individual was dropped from the analysis. The overall response rate was $12.7 \%$. Assuming a confidence level of $95 \%$, the confidence interval, based on 194 responses, is 6.5 .

Among the 194 participants, 97 (50\%) were male, and 97 (50\%) were female. Mean age of the participants was $25.98(S D=4.86)$, and $83 \%$ of students were born between 1990 and 1980, which means their ages range from 20-30 in 2010.

Eighty-three participants (43\%) were undergraduate students and 102 (53\%) were graduate students. Nine (5\%) students were studying in some kind of English program such as English as a Second or Other Language program (ESOL) or Intensive English Language Program (IELP).

Countries of origin. The students' countries of origin varied substantially. Participants came to PSU from more than 45 countries and regions (See Table 1). Prominent countries of origin are India $(n=30,16 \%)$, Japan ( $n=25,13 \%)$, Saudi Arabia ( $n=19,10 \%)$, China $(n=18,9 \%)$, and South Korea $(n=12,6 \%)$. 
Table 1

Participants' Countries of Origins

\begin{tabular}{|c|c|c|}
\hline & Frequency & Percent \\
\hline Argentina & 1 & .5 \\
\hline Austria & 3 & 1.5 \\
\hline Brazil & 3 & 1.5 \\
\hline Burkina Faso & 1 & .5 \\
\hline Cambodia & 1 & .5 \\
\hline Canada & 4 & 2.1 \\
\hline Cayman islands & 1 & .5 \\
\hline China & 18 & 9.3 \\
\hline Colombia & 2 & 1.0 \\
\hline Costa Rica & 2 & 1.0 \\
\hline Czechoslovakia & 1 & .5 \\
\hline England & 1 & .5 \\
\hline Ethiopia & 1 & .5 \\
\hline France & 2 & 1.0 \\
\hline Germany & 5 & 2.6 \\
\hline Hong Kong & 2 & 1.0 \\
\hline Hungary & 1 & .5 \\
\hline India & 30 & 15.5 \\
\hline Indonesia & 3 & 1.5 \\
\hline Iran & 8 & 4.1 \\
\hline Italy & 1 & .5 \\
\hline Japan & 25 & 12.9 \\
\hline Kenya & 1 & .5 \\
\hline Korea (South Korea) & 12 & 6.2 \\
\hline Kuwait & 1 & .5 \\
\hline
\end{tabular}


Table1

Continued

\begin{tabular}{|c|c|c|}
\hline & Frequency & Percent \\
\hline Libya & 2 & 1.0 \\
\hline Malaysia & 1 & .5 \\
\hline Mexico & 1 & .5 \\
\hline Mongolia & 1 & .5 \\
\hline Myanmar & 1 & .5 \\
\hline Nepal & 2 & 1.0 \\
\hline New Zealand & 1 & .5 \\
\hline Pakistan & 1 & .5 \\
\hline Palestine & 1 & .5 \\
\hline Panama & 1 & .5 \\
\hline Philippines & 1 & .5 \\
\hline Russia & 1 & .5 \\
\hline Saudi Arabia & 19 & 9.8 \\
\hline Sweden & 1 & .5 \\
\hline Taiwan & 7 & 3.6 \\
\hline Tajikistan & 1 & .5 \\
\hline Thailand & 6 & 3.1 \\
\hline Turkey & 1 & .5 \\
\hline United Arab Emirates & 2 & 1.0 \\
\hline Venezuela & 1 & .5 \\
\hline Viet Nam & 9 & 4.6 \\
\hline Zimbabwe & 1 & .5 \\
\hline Total & 192 & 99.0 \\
\hline Missing & 2 & 1.0 \\
\hline Total & 194 & 100.0 \\
\hline
\end{tabular}




\section{Personal Attributes}

Length of Residence at Portland State University. The length of residence at

Portland State University was calculated by the year and the term the participants first enrolled at PSU. Because the university is structured around four terms each year, I counted a year as four terms. Seventeen (9\%) students enrolled at the university in the term the survey was conducted (winter 2010), and this was the second term for 58 students (30\%). That is, more than one-third of the participants (39\%) started to study at PSU recently (within 20 weeks). Another one-third of participants ( $n=53,27 \%$ ) studied at PSU between three to six terms (9-18 months), and 34 students (18\%) had studied seven to ten terms.

Living arrangements. Among the 194 participants, 50 (26\%) were living on-campus while 144 (74\%) were living off-campus.

About $10 \%$ of each group (on and off campus combined) was living alone. This constitutes $21 \%$ of the total population $(n=41)$. In other words, the majority of students ( $n=153,79 \%$ ) were living with at least one person (See Table 2). Most students living on-campus had one housemate, while off-campus students tended to have more than one housemate. 
Table 2

Number of Housemates

\begin{tabular}{lccc}
\hline Number of Housemates & On-Campus & Off-campus & Total \\
\hline None & $18(9 \%)$ & $23(12 \%)$ & $41(21 \%)$ \\
1 person & $27(14 \%)$ & $57(29 \%)$ & $84(43 \%)$ \\
2 people & $4(2 \%)$ & $28(14 \%)$ & $32(16 \%)$ \\
3 people & 0 & $18(9 \%)$ & $18(9 \%)$ \\
4 people & $1(1 \%)$ & $11(6 \%)$ & $12(7 \%)$ \\
5 people & 0 & $3(2 \%)$ & $3(2 \%)$ \\
6 people & 0 & $1(1 \%)$ & $1(1 \%)$ \\
More than 7 people & 0 & $3(2 \%)$ & $3(2 \%)$ \\
\hline Total & $\mathbf{5 0 ( 2 6 \% )}$ & $\mathbf{1 4 4 ( 7 4 \% )}$ & $\mathbf{1 9 4 ( 1 0 0 \% ) ^ { \star }}$ \\
\hline
\end{tabular}

*These values may not total $100 \%$ due to rounding.

Table 3

Living Arrangements

\begin{tabular}{lccc}
\hline Type of Living Arrangement & On Campus & Off campus & Total \\
\hline Housemate / housemate & $26(17 \%)$ & $52(34 \%)$ & $78(51 \%)$ \\
Host family & 0 & $9(6 \%)$ & $9(6 \%)$ \\
Romantic partner & $1(1 \%)$ & $13(8 \%)$ & $14(9 \%)$ \\
Spouse / domestic partner / family & $5(3 \%)$ & $45(29 \%)$ & $50(33 \%)$ \\
Other & 0 & $2(1 \%)$ & $2(1 \%)$ \\
\hline Total & $\mathbf{3 2 ( 2 1 \% )}$ & $\mathbf{1 2 1 ( 7 9 \% )}$ & $\mathbf{1 5 3 ( 1 0 0 \% ) ^ { * }}$ \\
\hline
\end{tabular}

*These values may not total $100 \%$ due to rounding.

Among the participants who lived with someone, about half of them were living with a housemate $(n=78)$ (See Table 3). One-third of them were living with family members including a spouse or a domestic partner $(n=50)$. There were only 9 participants who are living with host families, and all of them were living off campus. 
Financial conditions. Financial conditions of the participants were measured in four ways. The first question asked if the participant owned a car in the U.S. The result shows 55 (28\%) students owned a car and the rest did not $(n=139,72 \%)$. The second question asked if the participants owned a computer in the U.S., and the results show the vast majority of the students did ( $n=188,97 \%)$; only six students did not have a computer (3\%). When asked about their Cost of Living per month (not including tuition), 26 (13\%) participants spent less than \$499 a month; 78 (40\%) spent between \$500 and \$999 and 48 (25\%) were between \$1000 and \$1499. A total of 23 (12\%) lived on \$1500 and \$1999, and 19 (10\%) had more than \$2000 for Cost of Living per month. The last question asked “Affluence,” that is, how often the participant worried about his or her financial situation. The results indicated that 50 participants (26\%) “always worried,” 51 (26\%) answered “often worried,” 62 (32\%) were “sometimes worried,” while 23 (12\%) were "rarely worried” and 8 (4\%) were "not worried at all.” This suggests that the majority of the participants worried about their financial situation to some extent, between "sometimes" to "always" ( $n=163,84 \%)$. 
Table 4

Comfort Level in English

\begin{tabular}{lccc}
\hline Comfort Level in English & $\begin{array}{c}\text { Native } \\
\text { speaker }\end{array}$ & $\begin{array}{c}\text { Non-native } \\
\text { speaker }\end{array}$ & Total \\
\hline Very uncomfortable & $9(5 \%)$ & $27(4 \%)$ & $36(19 \%)$ \\
Somewhat uncomfortable & 0 & $37(19 \%)$ & $37(19 \%)$ \\
Not sure & 0 & $15(8 \%)$ & $15(8 \%)$ \\
Somewhat comfortable & $5(3 \%)$ & $53(27 \%)$ & $58(30 \%)$ \\
Very comfortable & $6(3 \%)$ & $42(22 \%)$ & $48(25 \%)$ \\
\hline Total & $\mathbf{2 0 ( 1 0 \% )}$ & $\mathbf{1 7 4 ( 9 0 \% )}$ & $\mathbf{1 9 4 ( 1 0 0 \% ) *}$ \\
\hline
\end{tabular}

*These values may not total $100 \%$ due to rounding.

Comfort Level in English. Only 20 (10\%) participants identified themselves as native English speakers (Table 4). However, being a native English speaker does not guarantee that the participant has no language barrier. The results indicate that nine of the 20 native English speakers (45\%) felt "very uncomfortable” when they speak English. Five native speakers (3\%) chose "somewhat comfortable” and six (3\%) were "very comfortable."

Among non-native English speakers ( $n=174,90 \%)$, their comfort levels in English varied: 27 (14\%) were “very uncomfortable,” 37 (19\%) were "somewhat uncomfortable,” 15 (8\%) were "not sure,” 53 (27\%) were “somewhat comfortable,” and 42 (22\%) were "very comfortable.” 
The results indicate that the international students, both native and non-native English speakers, are bisected: some feel uncomfortable speaking English to some extent ( $n=73,38 \%)$ and others feel comfortable ( $n=106$, 55\%) speaking English.

English Proficiency. In addition to participants' Comfort Level in English, the study also asked their language proficiency; measuring the English score in the Test of English as a Foreign Language (TOEFL) and the Test of English for International Communication (TOEIC). The TOEFL scores are commonly used for university and college admissions to measure a student's English Proficiency. In contrast, TOEIC scores are often used to indicate one's communication skill in English for business purposes. In general, international students need to take the TOEFL exam to apply to an American university. According to the official Portland State University website, the minimum test score requirement for PSU admission is 68 in the internet-based TOEFL test, 550 in paper-based, and 213 in computer-based.

However, the study revealed that many international students did not recall their scores, and only 111 (57\%) participants remembered valid scores. ${ }^{3}$

\footnotetext{
${ }^{3}$ Each TOEFL test score range differs (e.g., from 0 to 120 for the paper-based test, and 310 to 677 for the paper-based test). Approximately 83 students failed to answer this question.
} 
Since there are three kinds of TOEFL tests, scores in paper-based and in computer-based tests were converted to internet-based (currently the most common method) by using a conversion table. ${ }^{4}$ Also, some participants only remembered their TOEIC scores, so I also converted them to an internet-based score using a conversion chart. ${ }^{5}$ If the student answered more than one score, the highest score was utilized. This converted score was labeled “English Proficiency.” The English Proficiency variable may not reflect participants’ current English levels accurately since they usually take the test before admission or shortly after they start to study at PSU. Some scores are several years old, so it is likely that students' English scores improved while taking classes and studying. Still, it is worthwhile to include an objective scale to measure the participants’ English Proficiency.

The results show that the vast majority of the participants who remembered their valid scores qualified to be eligible to study at PSU (105 out of 111), but the scores were dispersed from 68 (the minimum requirement by PSU) to 119 (120 is the maximum score in TOEFL).

\footnotetext{
${ }^{4}$ A conversion table was employed from the official website of the Educational Testing Service (ETS), which administers and scores TOEFL and TOEIC exams.

${ }^{5}$ TOEFL TOEIC score conversion table.
} 
There was no significant relationship between the participants’ Comfort Level in English and English Proficiency $(r=.112, p=.243)$.

\section{Representativeness}

Representativeness describes how well the sample of the study represents (or is similar to) the population of interest (Babbie, 2004). When a sample is similar to its population, the representativeness of the sample is high, and validity and reliability of the study will be enhanced. To check representativeness, I compared the sample with the population of international students at Portland State University. According to the website of the Office of Institutional Research and Planning, 63\% of international students were male $(n=987)$ and $37 \%$ were female $(n=568) .{ }^{6}$ Since $50 \%$ of the participants of the current study were female, women had greater representation in the sample.

Also, 66\% of the international students at PSU were undergraduates (including students in English programs) and 34\% were graduate students. However, my sample

\footnotetext{
${ }^{6}$ The data presented in the website are slightly different from the population sampled because sample was collected in winter 2010, prior to the publication of the website data.
} 
consisted of $48 \%$ undergraduate students and $53 \%$ graduate students. The sample has a balance of undergraduate and graduate students, while the population has two-thirds undergraduate students. Therefore graduate students were over-represented in the sample.

There were no data available regarding the age of international students, but $63 \%$ of all the students at Portland State University were between 21 to 30 years-old. Among the respondents, 78\% are between 21 and 31 . The sample is therefore slightly younger than all PSU students.

Prominent countries of origin for Portland State University students are Saudi Arabia ( $n=325)$, China $(n=180)$, India $(n=176)$, Japan $(n=136)$, and South Korea ( $n=116$ ). These five countries match with the most prominent countries of origin in the sample. There were no data available about other demographic characteristics, such as living arrangement, English Proficiency, or Cost of Living.

Overall, my sample was over-represented by women and graduate students compared to the international student population. Also, my sample includes a larger number of the younger generation (between 21 and 30 years old) compared to the all students at Portland State University. 


\section{Relationships among Independent Variables}

Among demographic variables, the study showed several statistically significant correlations. Participants' age is positively correlated with Length of Residence at Portland State University $(r=.286, p=.000)$ and Cost of Living ( $r h o=.282, p$

$=.000) .{ }^{7}$ Cost of Living is positively correlated with Comfort Level in English (rho

$=.217, p=.002)$, but negatively correlated with Number of Housemates $(r=-.194, p$

$=.007)$.

\section{Socializing with Friends}

Frequency of participants socializing with their PSU friends was measured by asking the participants how many times they: (1) studied, (2) ate a meal, (3) went to a restaurant or coffee shop, (4) went to a university-related event, (5) watched TV, (6) hosted a social gathering, (7) went to a party or a bar, and (8) engaged in other activities, with PSU friends in the last two weeks. Answer choices included: (1) never, (2) 1-3 times, (3) 4-6 times, (4) 7-9 times, (5)10-12 times, and (6) more than 13 times.

\footnotetext{
${ }^{7}$ Spearman correlations were used in relationship with categorical variables.
} 
These six choices intended to measure activities in two weeks (14 days). That is, the maximum frequency (more than 13 times) will be as often as “every day.”

Turning to the results, the majority of students studied with PSU friends ( $n=152$, $78 \%$ ), ate a meal ( $n=160,83 \%)$, and went to a restaurant or coffee shop ( $n=151$, $78 \%)$ at least once in the last two weeks. In contrast, the least common activities were watching TV and hosting a social gathering; more than $60 \%$ of participants never engaged these activities with friends in the last two weeks (Table 5).

The reliability test showed that the alpha coefficient for the eight items is .866; that is, the items have relatively high internal consistency. Therefore, I created a new variable labeled "Socializing with Friends” by aggregating all eight items. The possible range of Socializing with Friends measures was 8 - 48, where higher scores indicated a higher level of socializing. The mean was $16.52(S D=6.71)$. 
Table 5

Frequency of Socializing with Friends

\begin{tabular}{lccccccc}
\hline & & & & $7-9$ & $10-12$ & More than & \\
& Never & $1-3$ times & $4-6$ times & times & times & 13 times & Total $^{*}$ \\
\hline Studied & $42(22 \%)$ & $77(40 \%)$ & $39(20 \%)$ & $17(9 \%)$ & $5(3 \%)$ & $14(7 \%)$ & $194(100 \%)$ \\
Ate a meal & $34(18 \%)$ & $78(40 \%)$ & $34(18 \%)$ & $15(8 \%)$ & $14(7 \%)$ & $19(10 \%)$ & $194(100 \%)$ \\
Went a restaurant & $43(22 \%)$ & $95(49 \%)$ & $26(13 \%)$ & $13(7 \%)$ & $8(4 \%)$ & $9(5 \%)$ & $194(100 \%)$ \\
Went to an event & $80(41 \%)$ & $81(42 \%)$ & $18(9 \%)$ & $6(3 \%)$ & $6(3 \%)$ & $3(2 \%)$ & $194(100 \%)$ \\
Watched TV & $122(63 \%)$ & $48(25 \%)$ & $15(8 \%)$ & $5(3 \%)$ & $2(1 \%)$ & $2(1 \%)$ & $194(100 \%)$ \\
Hosted a gathering & $118(61 \%)$ & $57(29 \%)$ & $10(5 \%)$ & $6(3 \%)$ & 0 & $3(2 \%)$ & $194(100 \%)$ \\
Went to a party/bar & $90(46 \%)$ & $76(39 \%)$ & $18(9 \%)$ & $7(4 \%)$ & $1(1 \%)$ & $2(1 \%)$ & $194(100 \%)$ \\
Other activities & $64(33 \%)$ & $83(43 \%)$ & $34(18 \%)$ & $2(1 \%)$ & $3(2 \%)$ & $8(4 \%)$ & $194(100 \%)$ \\
\hline
\end{tabular}

*These values may not total $100 \%$ due to rounding.

\section{Satisfaction with Life at Portland State University}

Satisfaction with life at PSU was measured by adapting the "Satisfaction with

Life Scale” originated by Diener and colleagues (Diener, Emmons, Larsen \& Griffin, 1985) and modified for college settings by Ellison, Steinfield, and Lampe in 2007.

Items were as follows: (1) in most ways my life at Portland State University is close to my ideal, (2) the conditions of my life at PSU are excellent, (3) I am satisfied with my life at PSU, (4) so far I have gotten the important things I want at PSU, and (5) if I could re-live my time at PSU, I would not change anything. Responses were recorded on a 5-part Likert-type scale. 
Table 6

Life Satisfaction

\begin{tabular}{lcccccc}
\hline & Strongly & & & \multicolumn{3}{c}{ Strongly } \\
& Disagree & Disagree & Not Sure & Agree & Agree & Total* $^{*}$ \\
\hline Life at PSU is close to Ideal & $14(7 \%)$ & $43(22 \%)$ & $44(23 \%)$ & $81(42 \%)$ & $12(6 \%)$ & $194(100 \%)$ \\
Conditions of my life are excellent & $7(4 \%)$ & $45(23 \%)$ & $36(19 \%)$ & $91(47 \%)$ & $15(8 \%)$ & $194(100 \%)$ \\
I am satisfied with my life & $8(4 \%)$ & $37(19 \%)$ & $42(22 \%)$ & $89(46 \%)$ & $18(9 \%)$ & $194(100 \%)$ \\
I have gotten Important things & $8(4 \%)$ & $37(19 \%)$ & $42(22 \%)$ & $89(46 \%)$ & $18(9 \%)$ & $194(100 \%)$ \\
I would not change anything & $30(16 \%)$ & $61(31 \%)$ & $54(28 \%)$ & $38(20 \%)$ & $11(6 \%)$ & $194(100 \%)$ \\
\hline
\end{tabular}

*These values may not total $100 \%$ due to rounding.

As Table 6 shows, there is a common pattern in the participants' responses

except the fifth item. About half the participants (48-55\%) felt satisfaction (agreed or

strongly agreed) with each item, while 23-29\% of participants felt unsatisfied

(disagreed or strongly disagreed) and 19-23\% were not sure.

The fifth item "if I could re-live my time at PSU, I would not change anything” showed an inverse pattern from other four items. Only a quarter of the participants agreed with the statement ( $n=49,26 \%)$, and half the participants disagreed $(n=91$, $47 \%)$. One quarter of participants were not sure $(n=54,28 \%)$.

In summary, participants who were satisfied (agreed or strongly agreed)

outnumbered those who were not except for the fifth item. 
To confirm the actual internal consistency of the items, I conducted a reliability analysis. The alpha coefficient for the five items is .861. That is, the items have relatively high internal consistency. Therefore, I aggregated all items and created a new variable labeled "Life Satisfaction.” The possible range on the Life Satisfaction measure was 5 - 25, where higher scores indicated a higher level of satisfaction. The obtained range was 5 - 25, and the mean was $15.92(S D=4.20)$.

\section{Findings}

\section{Emotional Support from Friends}

The goal of Research Question 1 was to determine to what extent international students are vesting their expressive resources from new social capital. The current study measures "vesting expressive resource" by measuring the amount of emotional support the student receives from his or her PSU friends. In order to measure the amount of emotional support, I used the Communication Based Emotional Support Scale (CBESS), originally developed by Weber and Patterson in 1996.

Communication Based Emotional Support Scale consists of 13 items of emotional support behaviors. As Table 7 demonstrates, except for item 1 and 4, about 
half to three-quarters of participants (47-72\%) agreed with each item, and a smaller percentage of participants (7-19\%) disagreed. For example, 71\% $(n=137)$ of participants agreed with item 3 "When I tell My PSU friends about a problem, they pay attention” whereas $8 \%(n=15)$ disagreed.

Table 7

Friends Support

\begin{tabular}{lcllccc}
\hline & Strongly & & & & Strongly \\
& Disagree & Disagree & Not Sure & Agree & Agree & Total* $^{*}$ \\
\hline 1. Help & $19(10 \%)$ & $26(13 \%)$ & $62(32 \%)$ & $66(34 \%)$ & $21(11 \%)$ & $194(100 \%)$ \\
2. Listen & $6(3 \%)$ & $17(9 \%)$ & $54(28 \%)$ & $93(48 \%)$ & $24(12 \%)$ & $194(100 \%)$ \\
3. Pay attention & $4(2 \%)$ & $11(6 \%)$ & $42(22 \%)$ & $108(56 \%)$ & $29(15 \%)$ & $194(100 \%)$ \\
4. Deal with problems & $14(7 \%)$ & $33(17 \%)$ & $69(36 \%)$ & $64(33 \%)$ & $14(7 \%)$ & $194(100 \%)$ \\
5. Avoid ** & $2(1 \%)$ & $25(13 \%)$ & $64(33 \%)$ & $75(39 \%)$ & $28(14 \%)$ & $194(100 \%)$ \\
6. Good listeners & $5(3 \%)$ & $10(5 \%)$ & $67(35 \%)$ & $93(48 \%)$ & $19(10 \%)$ & $194(100 \%)$ \\
7. Supportive things & $4(2 \%)$ & $13(7 \%)$ & $54(28 \%)$ & $99(51 \%)$ & $24(12 \%)$ & $194(100 \%)$ \\
8. Something else to do** & $10(5 \%)$ & $27(14 \%)$ & $67(35 \%)$ & $73(38 \%)$ & $17(9 \%)$ & $194(100 \%)$ \\
9. Honest concern & $2(1 \%)$ & $11(6 \%)$ & $62(32 \%)$ & $96(50 \%)$ & $23(12 \%)$ & $194(100 \%)$ \\
10. Good advice & $2(1 \%)$ & $12(6 \%)$ & $42(22 \%)$ & $108(56 \%)$ & $30(16 \%)$ & $194(100 \%)$ \\
11. Discuss & $6(3 \%)$ & $20(10 \%)$ & $73(38 \%)$ & $74(38 \%)$ & $21(11 \%)$ & $194(100 \%)$ \\
12. Listen to my side & $4(2 \%)$ & $23(12 \%)$ & $66(34 \%)$ & $85(44 \%)$ & $16(8 \%)$ & $194(100 \%)$ \\
13. Make effort & $5(3 \%)$ & $16(8 \%)$ & $59(30 \%)$ & $92(47 \%)$ & $22(11 \%)$ & $194(100 \%)$ \\
\hline
\end{tabular}

*These values may not total $100 \%$ due to rounding.

**|tems 5 and 8 were reverse coded. Scores were converted. 
For the two exceptional items (numbers 1 and 4), the ratio of participants agreeing versus participants disagreeing is smaller than the other items. For item 1, “My PSU friends help me understand my thoughts and feelings,” 45\% ( $n=87)$ agreed and 23\% $(n=45)$ of participants disagreed. For item 4, "My PSU friends help me deal with problems,” 40\% $(n=78)$ agreed and 24\% $(n=47)$ disagreed.

Also, for each item 22-38\% of participants answered “not sure.” That is, about one-third of the participants were ambivalent about these 13 behaviors.

After examining the responses, I conducted a reliability analysis on the 13 items and found that these items have high internal consistency $(\alpha=.903)$. Therefore, I created a new variable labeled "Friends Support” by summing the 13 items. The possible range on the Friends Support was 13 to 65, where higher scores indicated that participants perceived more emotional support from friends. The obtained range was 14 to 64 , and the mean score was $45.66(S D=8.10)$.

To address the research question, I found that $47-72 \%$ of participants felt they were receiving emotional support (i.e., investing expressive resources) in 11 behaviors out of 13. In contrast, 7-19\% of participants did not perceive emotional support from 
friends in each behavior. To answer Research Question 1, the majority of international students perceived that they vest expressive resources from their new social capital.

\section{Emotional Support from the Participant}

The purpose of Research Question 2 was to examine to what extent international students invest their expressive resources (i.e., providing emotional support) in new social capital. In order to determine the answer, the second emotional scale asked the degree to which participants are supporting their friends. Each CBESS scale has 13 items describing the same content with the following exception: For the first scale, "friends" were the target, and for the second scale, "I" is the target. The second scale measures to what extent participants personally provide emotional support.

Table 8 shows, except items 5 and 8, a large percentage of the participants (66-90\%) agreed with each statement. For item 3 "When my PSU friends tell me about a problem, I pay attention,” 90\% of the participants $(n=173)$ agreed. For each item, there is a small ratio of participants who disagreed (1-9\%). Six items included no participants who strongly disagreed. Also, less than one-third (9-28\%) of participants were "not sure" in each item. 
Two items hold a different pattern from the others. For item 5, "I avoid my PSU

friends when they are upset," $58 \%(n=113)$ agreed and one-quarter $(23 \%)$ of

participants disagreed. For item 8 "When my PSU friends want to talk to me, I seem to have something else to do," only $47 \%$ ( $n=92)$ agreed while one-third (33\%) of the participants disagreed.

Table 8

Participant Support

\begin{tabular}{lcccccc}
\hline & $\begin{array}{c}\text { Strongly } \\
\text { Disagree }\end{array}$ & Disagree & Not Sure & Agree & Agree & Tota* $^{*}$ \\
\hline 1. Help & $4(2 \%)$ & $13(7 \%)$ & $50(26 \%)$ & $100(52 \%)$ & $27(14 \%)$ & $194(100 \%)$ \\
2. Listen & $1(1 \%)$ & $4(2 \%)$ & $28(14 \%)$ & $121(62 \%)$ & $40(21 \%)$ & $194(100 \%)$ \\
3. Pay attention & $1(1 \%)$ & $3(2 \%)$ & $17(9 \%)$ & $133(69 \%)$ & $40(21 \%)$ & $194(100 \%)$ \\
4. Deal with problems & $1(1 \%)$ & $13(7 \%)$ & $51(26 \%)$ & $104(54 \%)$ & $25(13 \%)$ & $194(100 \%)$ \\
5. Avoid ** & $6(3 \%)$ & $38(20 \%)$ & $37(19 \%)$ & $76(39 \%)$ & $37(19 \%)$ & $194(100 \%)$ \\
6. Good listeners & $1(1 \%)$ & $5(3 \%)$ & $37(19 \%)$ & $115(59 \%)$ & $36(19 \%)$ & $194(100 \%)$ \\
7. Supportive things & 0 & $2(1 \%)$ & $40(21 \%)$ & $114(59 \%)$ & $38(20 \%)$ & $194(100 \%)$ \\
8. Something else to do** & $11(6 \%)$ & $52(27 \%)$ & $39(20 \%)$ & $70(36 \%)$ & $22(11 \%)$ & $194(100 \%)$ \\
9. Honest concern & 0 & $5(3 \%)$ & $35(18 \%)$ & $114(59 \%)$ & $40(21 \%)$ & $194(100 \%)$ \\
10. Good advice & 0 & $6(3 \%)$ & $40(21 \%)$ & $105(54 \%)$ & $43(22 \%)$ & $194(100 \%)$ \\
11. Discuss & 0 & $11(6 \%)$ & $54(28 \%)$ & $98(51 \%)$ & $31(16 \%)$ & $194(100 \%)$ \\
12. Listen to friends' side & 0 & $11(6 \%)$ & $31(16 \%)$ & $121(62 \%)$ & $31(16 \%)$ & $194(100 \%)$ \\
13. Make effort & 0 & $5(3 \%)$ & $42(22 \%)$ & $112(58 \%)$ & $35(18 \%)$ & $194(100 \%)$ \\
\hline
\end{tabular}

*These values may not total $100 \%$ due to rounding.

**Item 5 and 8 were reversed questions. Scores were converted. 
The reliability analysis showed that the 13 items share high internal consistency $(\alpha=.850)$. Therefore, I created a new variable labeled "Participant Support” by aggregating the 13 items. Answer range was from 30 to 65, where higher scores indicate that participants are providing more emotional support to their friends. The mean score was $49.59(S D=6.25)$.

To address Research Question 2, I found that $66-90 \%$ of international students felt they provided emotional support to their friends. With the exception of two behaviors, less than 10\% (1-9\%) of participants disagreed. Across all items, less than one-third (9-28\%) of participants answered "not sure. Thus, answering Research Question 2, the majority of international students invest their expressive resources in new social capital.

\section{Relationship between Friends Support and Participant Support}

Research Question 3 probes the relationship between "investing” and "vesting” expressive resources. Recall that to address the two previous research questions, I created two new variables by aggregating items in each scale: Friends Support from the scale measuring vesting expressive resources, and Participant Support from the 
scale measuring investing expressive resources. In order to answer Research Question 3, I examined the relationship between Friends Support and Participant Support.

In comparing Friend Support and Participant Support, I found that participants showed slightly different response patterns on both scales. In Friends Support, except for a few items, about half to three-quarters (47-72\%) of participants acknowledged receiving emotional support (i.e., vesting expressive resources) from friends, but 7-19\% of participants disagree. In Participant Support, on the other hand, two-thirds (66\%) to $90 \%$ of participants claimed they provided emotional support (i.e., invest expressive resources) to friends while less than $9 \%$ of participants claimed that they did not provide emotional support to their friends. In addition, Participant Support ( $M$ $=49.60, S D=6.25)$ was higher than Friends Support $(M=45.66, S D=8.10)$. Paired Samples t-tests showed that the difference between the two means is statistically significant $(t=-7.737, d f=193, p=.000)$. These results suggest that the participants perceived that they provided support to their friends more often than their friends provided support to them.

To address Research Question 3, I found that Participant Support (investing expressive resources) and Friends Support (vesting expressive resources) had a 
statistically significant positive correlation $(r=.539, p=.000)$ and Participant Support had a higher overall mean.

\section{Relationship between Socializing with Friends and Friends Support}

Research Question 4a asked if informal social interaction with friends such as eating meals and studying together (Socializing with Friends) influences participants' vesting expressive resources (Friends Support). Social interaction was measured as the "Socializing with Friends" scale as I described earlier. Therefore, in order to address the Research Question 4a, I examined the causal relationship between Socializing with Friends and Friends Support.

Socializing with Friends and independent variables. First, I examined how Socializing with Friends is related to other independent variables. The relationship between Socializing with Friends and Length of Residence at Portland State University is weak but statistically significant $(r=.154, p<.05)$. Socializing with Friends, however, did not have statistically significant relationships with participants' age ( $r=-.064, p=.377)$, English Proficiency $(r=-.030, p=.757)$, Comfort Level in English $(r=-.029, p=.688)$, Number of Housemates $(r=-.079, p=.271)$, Affluence 
(how much they worried about financial situation) $(r=.102, p=.158)$, and Cost of Living ( $r h o=-.031, p=.671)$.

In order to examine the effect of the nominal variables, independent sample t-tests were run (Table 9). However, the results indicated that there were no significant differences in the means of the Socializing with Friends scale with the following items: male $(n=97, M=17.06, S D=6.59)$ and female $(n=97, M=15.97, S D=$ 6.82) $(t=1.135, d f=192, p=.258)$; graduate students $(n=102, M=16.96, S D=$ 6.77) and undergraduate students $(n=83, M=16.23, S D=6.90)(t=-.725, d f=183$, $p=.469)$; between students living on-campus $(n=50, M=16.64, S D=5.76)$ and off-campus $(n=144, M=16.47, S D=7.03)(t=.152, d f=192, p=.879)$; and between native English speakers ( $n=20, M=17.40, S D=6.06)$ and non-native English speakers $(n=174, M=16.41, S D=6.79)(t=.621, d f=192, p=.535)$. 
Table 9

Socializing with Friends Independent Sample t-tests

\begin{tabular}{|c|c|c|c|c|c|c|c|}
\hline & & $N$ & $d f$ & $T$ & Sig.(2-tailed) & $M$ & $S D$ \\
\hline \multirow[t]{8}{*}{ Socializing with Friends } & Male & 97 & 192 & 1.135 & .258 & 17.06 & 6.59 \\
\hline & Female & 97 & & & & 15.97 & 6.82 \\
\hline & Undergraduate & 83 & 183 & -.725 & .469 & 16.23 & 6.90 \\
\hline & Graduate & 102 & & & & 16.96 & 6.77 \\
\hline & Living on-campus & 50 & 192 & .152 & .879 & 16.64 & 5.76 \\
\hline & Living off-campus & 144 & & & & 16.47 & 7.03 \\
\hline & Native Speaker & 20 & 192 & .621 & .535 & 17.40 & 6.06 \\
\hline & Non-native Speaker & 172 & & & & 16.41 & 6.79 \\
\hline
\end{tabular}

Independent variables and Friends Support. Second, I examined how other

independent variables are related to Friends Support. I found that Friends Support did not have a statistically significant relationship with participants' age $(r=-.058, p$ $=.423)$, English Proficiency $(r=.046, p=.632)$, Comfort Level in English $(r=-.054$, $p=.451)$, Length of Residence at PSU ( $r=-.066, p=.363)$, Number of Housemate $(r$ $=-.058, p=.423)$, Affluence $(r=.013, p=.856)$, or Cost of Living $(r h o=.074, p$ $=.308){ }^{8}$

${ }^{8}$ Spearman correlations were used in relationships with categorical variables. 
In order to find out the relationship of Friends Support with nominal variables, I

conducted independent sample t-tests. The results indicated that there are no

significant differences in the means of Friends Support with the following items: male

$(n=97, M=44.61, S D=8.08)$ and female $(n=97, M=46.71, S D=8.03)(t=-1.818$,

$d f=192, p=.071)$; graduate students $(n=102, M=46.11, S D=8.49)$ and

undergraduate students $(n=83, M=45.41, S D=7.79)(t=-.577, d f=183, p=.565)$;

students living on-campus $(n=50, M=46.64, S D=9.06)$ and off-campus $(n=144$,

$M=45.32, S D=7.75)(t=.993, d f=192, p=.322)$; and native English speakers $(n=$

20, $M=47.00, S D=7.16)$ and non-native English speakers' scores $(n=174, M=$

45.51, $S D=8.21)(t=.780, d f=192, p=.436)($ See Table 10$)$.

Table 10

Friends Support Independent Sample t-tests

\begin{tabular}{llllcccr}
\hline & $\boldsymbol{n}$ & $\boldsymbol{d f}$ & $\boldsymbol{t}$ & \multicolumn{1}{c}{ Sig.(2-tailed) } & $\boldsymbol{M}$ & \multicolumn{1}{c}{$\boldsymbol{S D}$} \\
\hline Friends Support & Male & 97 & 192 & -1.818 & .071 & 44.61 & 8.08 \\
& Female & 97 & & & & 46.71 & 8.03 \\
& Undergraduate & 83 & 183 & -.577 & .565 & 45.41 & 7.79 \\
& Graduate & 102 & & & & 46.11 & 8.49 \\
& Living on-campus & 50 & 192 & .993 & .332 & 46.64 & 9.06 \\
& Living off-campus & 144 & & & & 45.32 & 7.75 \\
& Native Speaker & 20 & 192 & .780 & .436 & 47.00 & 7.16 \\
& Non-native Speaker & 172 & & & & 45.51 & 8.21 \\
\hline
\end{tabular}


Turning back to the Research Question 4a, the results showed that Socializing

with Friends had a statistically significant correlation with Friends Support $(r=.360, p$

$<.01)$. To examine the influence of Socializing with Friends on Friends Support, a

regression analysis was run. Five blocks were entered in the following order:

demographics; personal attributes (e.g., Cost of Living and Comfort Level in English);

Life Satisfaction; Participant Support; and Socializing with Friends. ${ }^{9}$ Results are

shown in Table 11.

The result showed that after accounting for other variables (demographics,

personal attributes, Life Satisfaction, and Participants Support), Socializing with

Friends explained $4 \%$ of the variance on Friends Support $(\beta=.229, p=.001) .{ }^{10}$ The

largest contributor to the overall regression was Participant Support, which contributed

$26 \%$ of the variance. Total R-square was .320.

\footnotetext{
${ }^{9}$ Life Satisfaction is a dependent variable of Friends Support and Participant Support, but the process can be cyclical as I previously noted; therefore, Life Satisfaction was added in the analysis.

${ }^{10} \beta=$ Weighted Beta.
} 
Table 11

Predictors of Friends Support

\begin{tabular}{llll}
\hline Dependent Variable & Independent Variable & $\boldsymbol{\beta}$ & $\boldsymbol{R}^{2}$ \\
\hline Friends Support & Demographics & & \\
& Age & -.017 & \\
& Gender & .117 & .007 \\
& Personal Attributes & & \\
$\quad$ Number of Terms & -.097 & \\
Number of Housemates & -.082 & \\
$\quad$ Cost of Living & .011 & \\
$\quad$ Affluence & -.038 & \\
$\quad$ Comfort level in English & -.053 & .013 \\
& Life Satisfaction & .068 & .028 \\
& Participant Support & $.428^{\star \star \star}$ & .281 \\
& Socializing with Friends & $.229^{\star \star \star}$ & .320 (total $R^{2}$ ) \\
\hline
\end{tabular}

Note. $n=193$

a. Women are coded positive.

b. $\beta=$ weighted Beta.

${ }^{*} p \leq .05$

${ }^{\star \star} p \leq .01$

$* \star p \leq .001$

In addressing Research Question 4a, I found that Socializing with Friends

contributed $4 \%$ of the variance on Friends Support. That is, social interaction with

friends has a small but statistically significant influence on international students'

vesting expressive resources. 


\section{Relationship between Socializing with Friends and Participant Support}

Research Question 4b asked if informal social interaction with friends

influences the degree to which participants invest expressive resources. Social interaction was measured by the Socializing with Friends scale and investing expressive resources are measured by Participant Support. In order to address the Research Question 4b, I examined the causal relationship between Socializing with Friends and Participant Support.

Independent variables and Participant Support. Before turning to the research question, I examined relationships between independent variables and Participant Support. Participant Support had a weak but statistically significant correlation with Cost of Living ( $r h o=.149, p=.038$ ). Participant Support, however, did not have a significant correlation with participants’ age $(r=.019, p=.794)$, English Proficiency $(r=-.030, p=.757)$, Comfort Level in English $(r=-.029, p$ $=.688)$, Length of Residence at PSU ( $r=-.041, p=.570)$, Number of Housemates $(r$ $=-.079, p=.271)$, or Affluence $(r=.102, p=.158)$. 
In order to examine the relationship with the nominal independent variables, independent sample t-tests were run. The results indicate that there are no significant differences in the means of Participant Support with the following items: male $(n=97$, $M=49.16, S D=6.01)$ and female $(n=97, M=50.02, S D=6.49)(t=-.953, d f=$ $192, p=.342)$; graduate students $(n=102, M=50.19, S D=5.95)$ and undergraduates $(n=83, M=49.29, S D=6.61)(t=-.970, d f=183, p=.333)$; living on-campus $(n=50, M=49.28, S D=6.28)$ and off-campus $(n=144, M=49.70, S D$ $=6.26)(t=-.410, d f=192, p=.682)$; and between native English speakers $(n=20$, $M=50.15, S D=4.30)$ and non-native English speakers $(n=174, M=49.53, S D=$ 6.44) $(t=.420, d f=192, p=.675)$ (See Table 12).

Turning back to Research Question 4b, I examined the relationship between Socializing with Friends and Participant Support. I found that Socializing with Friends had a statistically significant correlation with Participant Support $(r=.338, p<.01)$. 
Table 12

Participant Support Independent Sample t-tests

\begin{tabular}{llrrrrrr}
\hline & $\boldsymbol{N}$ & $\boldsymbol{d f}$ & $\boldsymbol{t}$ & Sig.(2-tailed) & $\boldsymbol{M}$ & $\boldsymbol{S} \boldsymbol{D}$ \\
\hline Participant Support & Male & 97 & 192 & -.953 & .342 & 46.16 & 6.01 \\
& Female & 97 & & & & 50.02 & 6.49 \\
& Undergraduate & 83 & 183 & -.970 & .333 & 49.29 & 6.61 \\
& Graduate & 102 & & & & 50.19 & 5.95 \\
& & & & & & \\
& Living on-campus & 50 & 192 & -.410 & .682 & 49.28 & 6.28 \\
& Living off-campus & 144 & & & & 49.70 & 6.26 \\
& & & & & & \\
& Native Speaker & 20 & 192 & .420 & .675 & 50.15 & 4.30 \\
& Non-native Speaker & 172 & & & & 49.53 & 6.44
\end{tabular}

To examine the influence of Socializing with Friends on Participant Support, a regression analysis was run. Five blocks were entered in the following order: demographics; personal attributes; Life Satisfaction; Friends Support; and Socializing with Friends. Results are shown in Table 13.

The results showed that after accounting for other variables (demographics, personal attributes, Life Satisfaction, and Friends Support), Socializing with Friends explained 3\% of variance on Participant Support $(\beta=.201, p=.004)$. The largest contributor to the overall regression was Friends Support, which contributed 25\% of the variance. Total R-square was .293. 
In addressing Research Question 4b, I found that Socializing with Friends

contributed 3\% of the variance on Participant Support; social interaction with friends

has a small but statistically significant influence on international students' investing of

expressive resources.

Table 13

Predictors of Participant Support

\begin{tabular}{|c|c|c|c|}
\hline Dependent Variable & Independent Variable & $\beta$ & $R^{2}$ \\
\hline \multicolumn{4}{|c|}{ Participant Support Demographic } \\
\hline & Age & .045 & \\
\hline & Gender & .044 & -.006 \\
\hline & \multicolumn{3}{|l|}{ Personal Attributes } \\
\hline & Number of Terms & -.047 & \\
\hline & Number of Housemates & -.018 & \\
\hline & Cost of Living & .080 & \\
\hline & Affluence & .089 & \\
\hline & Comfort level in English & -.033 & .008 \\
\hline & Life Satisfaction & -.048 & .006 \\
\hline & Friends Support & $.445^{\star \star \star}$ & .265 \\
\hline & Socializing with Friends & $.201^{\star \star}$ & $.293\left(\right.$ total $\left.R^{2}\right)$ \\
\hline
\end{tabular}

Note. $n=193$

a. Women are coded positive.

b. $\beta=$ weighted Beta.

${ }^{*} p \leq .05$

${ }^{* *} p \leq .01$

${ }^{\star * \star} p \leq .001$ 


\section{Life Satisfaction and Friends Support}

Research Question 5a asked how the degree of vesting expressive resources (i.e., receiving emotional support) influences international students' life satisfaction.

Students' satisfaction about college life was measured by the Life Satisfaction Scale.

Life Satisfaction and independent variables. First, I examined the relationship

between Life Satisfaction and the independent variables. I found that Socializing with

Friends had a statistically significant correlation with Life Satisfaction $(r=.209, p$

$=.003)$. The study also showed that Life Satisfaction is significantly correlated with

Number of Housemates $(r=.150, p=.037)$. Independent sample t-tests also indicated

the means of Life Satisfaction of the participant who are living with someone $(n=153$,

$M=16.35, S D=4.28)$ are notably higher than those living alone $(n=41, M=14.32$,

$S D=3.47)(t=-2.805, d f=192, p=.006)$.

Life Satisfaction, however, did not have a statistically significant relationship

with the participants' age $(r=-.053, p=.462)$, English Proficiency $(r=.070, p=.465)$,

Comfort Level in English $(r=-.092, p=.200)$, Length of Residence at Portland State

University $(r=-.025, p=.729)$, Affluence $(r=.129, p=.072)$, and Cost of Living

$($ rho $=-.042, p=.558)$. 
Independent sample t-tests indicated that there are no significant differences in the means of Life Satisfaction with the following items: male ( $n=97, M=15.96, S D$ $=4.09)$ and female $(n=97, M=15.89, S D=4.33)(t=.119, d f=192, p=.905)$; between graduate students $(n=102, M=16.29$, $S D=4.50)$ and undergraduate students $(n=83, M=15.34, S D=3.85)(t=-1.534, d f=183, p=.127)$; between students living on-campus ( $n=50, M=16.00, S D=3.64)$ and off-campus $(n=144$, $M=15.90, S D=4.39)(t=.151, d f=192, p=.880)$; and between native English speakers $(n=20, M=14.90, S D=4.14)$ and non-native English speakers $(n=174, M$ $=16.04, S D=4.20)(t=-1.151, d f=192, p=.251)($ See Table 14).

Table 14

Life Satisfaction Independent Sample t-tests

\begin{tabular}{lllccccc}
\hline & & $\boldsymbol{N}$ & $\boldsymbol{d f}$ & $\boldsymbol{t}$ & \multicolumn{1}{c}{ Sig.(2-tailed) } & $\boldsymbol{M}$ & $\boldsymbol{S} \boldsymbol{S}$ \\
\hline Life Satisfaction & Male & 97 & 192 & .119 & .905 & 15.96 & 4.09 \\
& Female & 97 & & & & 15.89 & 4.33 \\
& Undergraduate & 83 & 183 & -1.534 & .127 & 15.34 & 3.85 \\
& Graduate & 102 & & & & 16.29 & 4.50 \\
& Living on-campus & 50 & 192 & .151 & .880 & 16.00 & 3.64 \\
& Living off-campus & 144 & & & & 15.90 & 4.39 \\
& Native Speaker & 20 & 192 & -1.151 & .251 & 14.90 & 4.14 \\
& Non-native Speaker & 172 & & & & 16.04 & 4.20 \\
\hline
\end{tabular}


Turning back to Research Question 5a, which asked how vesting expressive resources (i.e., Friends Support) influenced Life Satisfaction, I found that Life Satisfaction is positively correlated with Friends Support $(r=.149, p<.05)$.

To examine the influence of demographic variables, Socializing with Friends, Friends Support, and Participant Support, regressions were run. Five blocks were entered in the following order: demographics, personal attributes, Socializing with Friends, Participant Support, and Friends Support. Results are shown in Table 15. The result showed that after accounting for all other variables (demographics, personal attributes, Socializing with Friends, and Participant Support), Friends Support did not have a statistically significant contribution on Life Satisfaction. ( $\beta$ $=.095, p=.278)$. The largest contributor to the overall regression was Socializing with Friends, which explained $4 \%$ of variance on Life Satisfaction $\left(R^{2}=.049\right)$. Total R-square was .050.

In addressing Research Question 5a, I did not find any significant contribution of Friends Support (vesting expressive resources) on Life Satisfaction. 
Table 15

Predictors of Life Satisfaction (1)

\begin{tabular}{llll}
\hline Dependent Variable & Independent Variable & $\boldsymbol{\beta}$ & $\boldsymbol{R}^{2}$ \\
\hline Life Satisfaction & Demographics & & \\
& Age & -.025 & \\
& Gender & .030 & -.008 \\
& Personal Attributes & & \\
$\quad$ Number of Terms & -.014 & \\
$\quad$ Number of Housemates & .139 & \\
$\quad$ Cost of Living & .005 & \\
$\quad$ Affluence & .118 & \\
$\quad$ Comfort level in English & -.091 & .011 \\
& Socializing with Friends & $.2066^{\star}$ & .053 \\
& Participant Support & -.065 & .049 \\
& Friends Support & -.095 & $.050 \quad$ (total $R^{2}$ ) \\
& & &
\end{tabular}

Note. $n=193$

a. Women are coded positive.

b. $\beta=$ weighted Beta.

${ }^{*} p \leq .05$

${ }^{* *} p \leq .01$

$* \star p \leq .001$

\section{Life Satisfaction and Participant Support}

Research Question 5b asked how the degree of investing expressive resources

(i.e., providing emotional support) influences international students’ life satisfaction.

Recall that, investing expressive resources is measured by the Participant Support

scale. 
I found that there is no statistically significant relationship between Life

Satisfaction and Participant Support $(r=.079, p=.271)$. To examine the influence of independent variables, another regression was run. Five blocks were entered in the following order: demographics, personal attributes, Socializing with Friends, Friends Support, and Participant Support. Results are shown in Table 16.

Table 16

Predictors of Life Satisfaction (2)

\begin{tabular}{llll}
\hline Dependent Variable & Independent Variable & $\boldsymbol{\beta}$ & $\boldsymbol{R}^{2}$ \\
\hline Life Satisfaction & Demographic & & \\
& Age & -.025 & \\
& Gender & .030 & -.008 \\
& Personal Attributes & & \\
$\quad$ Number of Terms & -.014 & \\
$\quad$ Number of Housemates & .139 & \\
$\quad$ Cost of Living & .005 & \\
$\quad$ Affluence & .118 & \\
$\quad$ Comfort Level in English & -.091 & .011 \\
& Socializing with Friends & $.2066^{\star}$ & .053 \\
& Friends Support & .095 & .052 \\
& Participant Support & -.065 & $.050 \quad$ (total $R^{2}$ ) \\
& & &
\end{tabular}

Note. $n=193$

a. Women are coded positive.

b. $\beta=$ weighted Beta.

${ }^{*} p \leq .05$

${ }^{* *} p \leq .01$

$\star \star \star x p .001$ 
The result showed that after accounting for all other variables (demographics,

personal attributes, Socializing with Friends, and Friends Support), Participant

Support did not have a statistically significant contribution on Life Satisfaction. ( $\beta=$

$-.065, p=.450)$. Total R-square was .050.

In addressing Research Question 5b, I did not find any significant contribution of Participant Support (investing expressive resources) on Life Satisfaction.

\section{Post Hoc Analysis}

\section{Differences in the Gap between Participant Support and Friends Support}

During the pilot study and after the data collection, I received feedback about the survey from two Japanese friends. Both said that it was difficult for them to evaluate the level of emotional support they were giving to their friends. "I feel resistance to choose 'strongly agree' about what I am doing for my friends while I can easily choose 'strongly agree' for what my friends do for me," one friend said. The other friend predicted that Participant Support would score lower than Friends Support for the same reason. However, the results showed an overall higher Friends Support than Participant Support. Since this feedback came from Japanese students, I wondered if 
there was any cultural influence on the results. I decided to see if there were any differences by country in the gap between Participant Support and Friends Support.

As I previously stated, a paired samples t-test showed that Participant Support $(M=49.60, S D=6.25)$ was significantly higher than Friends Support $(M=45.66, S D$ $=8.10)(t=-7.737, d f=193, p=.000)$. However, when I conducted a paired samples t-test by country of origin, the gap varied depending on the country.

There are five countries that have the most participants: India $(n=30,16 \%)$, Japan $(n=25,13 \%)$, Saudi Arabia $(n=19,10 \%)$, China $(n=18,9 \%)$, and South Korea $(n=12,6 \%)$. For these five countries, five separate paired samples t-tests were run (See Table 17). Note, however, that the number of students in most categories fell below 30, which means multivariate analyses (such as t-tests) are below reliability standards (Babbie, 2004, p. 141). With this in mind, I approach the results below with caution.

The results indicated the two types of support had a statistically significant gap among participants from Saudi Arabia and India: among Saudi Arabian students, Participant Support $(M=51.63, S D=6.50)$ was higher than Friends Support $(M=$ 44.37, $S D=7.06)(t=-3.764, d f=18, p=.001)$; Indian Students' Participant Support 
$(M=50.03, S D=4.69)$ was also higher than Friends Support $(M=46.13, S D=7.61)(t$

$=-2.996, d f=29, p=.006)$.

In contrast, the gaps between the two types of support were not significant for Chinese, Korean, and Japanese students: for Chinese students, Participant Support ( $M$ $=50.72, S D=6.36)$ and Friends Support $(M=47.72, S D=8.67)(t=-1.751, d f=17, p$ $=.098)$; for Korean students, Participant Support $(M=44.833, S D=5.15)$ and Friends Support $(M=44.33, S D=6.85)(t=-.420, d f=11, p=.683)$; and for Japanese students, Participant Support $(M=48.08, S D=7.25)$ and Friends Support $(M=47.36, S D$ =7.99) $(t=-.700, d f=24, p=.491)$.

In summary, there seems to be a gap between the two types of support depending on the student's country of origin. It should be noted, however, that the sample sizes were small. Students from Saudi Arabia and India, like the majority of students, perceive that they provide more emotional support than they receive; on the other hand, students from East Asia (China, Korea, and Japan) seem to perceive that they receive as much emotional support as they provide. 
Table 17

Paired Samples t-tests: Participant Support and Friends Support by Country of Origin

\begin{tabular}{lllccccc}
\hline & & $\boldsymbol{N}$ & $\boldsymbol{d f}$ & $\boldsymbol{t}$ & Sig.(2-tailed) & $\boldsymbol{M}$ & \multicolumn{1}{c}{$\boldsymbol{S D}$} \\
\hline Saudi Arabia & Participant Support & 19 & 18 & -3.764 & .001 & 51.63 & 6.50 \\
& Friends Support & 19 & & & & 44.37 & 7.06 \\
India & Participant Support & 30 & 29 & -2.996 & .006 & 50.03 & 4.69 \\
& Friends Support & 30 & & & & 46.13 & 7.61 \\
China & Participant Support & 18 & 17 & -1.751 & .098 & 50.72 & 6.36 \\
& Friends Support & 18 & & & & 47.72 & 8.67 \\
Korea & Participant Support & 12 & 11 & -.420 & .683 & 44.83 & 5.15 \\
& Friends Support & 12 & & & & 44.33 & 6.85 \\
& Participant Support & 25 & 24 & -.700 & .491 & 48.08 & 7.25 \\
Japan & Friends Support & 25 & & & & 47.36 & 7.99 \\
\hline
\end{tabular}




\section{Chapter 6}

\section{DISCUSSION}

From the communication perspective, social capital is a communicative process

of giving and receiving resources_-investing and vesting_-among individuals. This aspect of the concept has been overlooked in past research. The current study attempts to examine this interactive process, particularly in expressive resources. The results show a moderately strong and positive correlation between giving and receiving expressive resources among international students. Furthermore, informal social interactions with friends predict these two behaviors. In this chapter, I will interpret these findings and discuss the significance of the study. I will also state the limitations and future prospects of the study.

\section{Results Summary}

The results include several statistically significant relationships. First, the two social capital scales, Friends Support and Participant Support, are positively correlated. 
Second, Socializing with Friends is found to be a weak but positive predictor of both Friends Support and Participant Support. Third, Life Satisfaction has no causal relationships with these two types of support; it has only a weak correlation with Friends Support and no significant correlation with Participant Support. Fourth, personal attributes (except for Cost of Living) do not have any significant relationships with either Friends Support or Participant Support. Figure 1 illustrates correlations between variables.

Figure1

Pearson Correlations between Variables

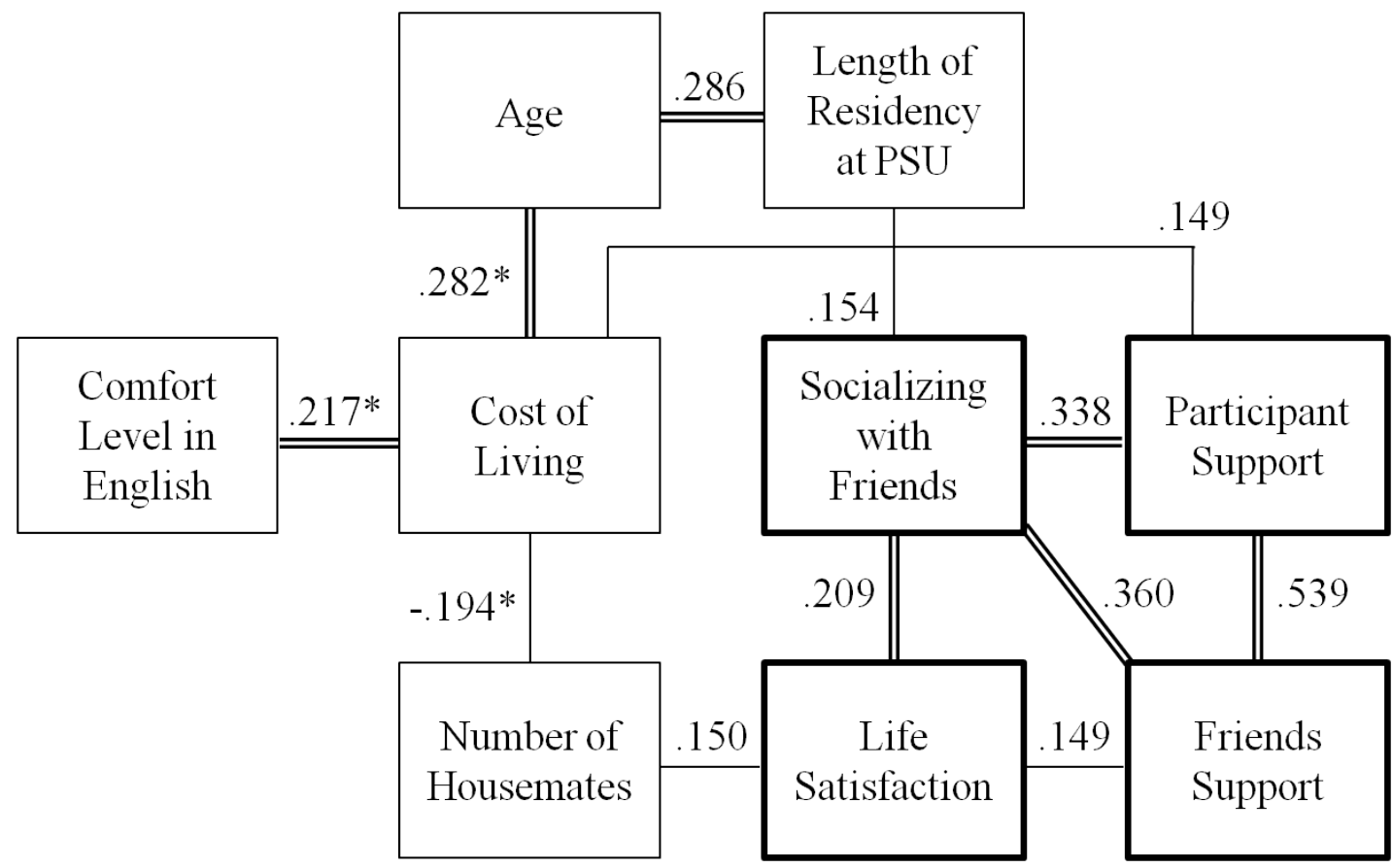

*Because “Cost of Living” is an ordinal variable, I used Spearman’s rho. 


\section{Friends Support: Vesting Expressive Resources}

The current study concerns two parts of the communicative process in social capital; investing and vesting of the participant's expressive resources. Research Question 1 asked to what extent international students are vesting (receiving) their expressive resources from their friends at the university. The results indicate international students do receive emotional support; they are vesting expressive resources from their social capital. Some students perceive more support than others. However, none of the personal attributes and demographic variables has a statistically significant relationship with Friends Support. For example, counter to my assumption, Length of Residency at Portland State University (PSU) does not have a direct impact on Friends Support $(r=-.054, p=.451)$. I assumed students who have studied longer at PSU are more likely to receive more emotional support. However, instead of a direct relationship with Friends Support, Length of Residency at PSU has a weak but positive relationship with Socializing with Friends, which has a moderately strong correlation with Friends Support. These results imply that participants who have been studying longer at PSU are more likely to socialize with their friends; and participants who socialize with friends often are more likely to perceive that they receive 
emotional support from friends. However, time in residence at PSU itself does not guarantee the receipt of emotional support. The current study shows that actual and concrete interaction with friends is an important component to predict the vesting of expressive resources in social capital.

\section{Participant Support: Investing Expressive Resources}

Paired with Research Question 1, Research Question 2 asked to what extent international students invest their expressive resources (i.e., providing emotional support) in new social capital. The results show that international students perceive themselves as giving emotional support to their friends. In relationship with other variables, Participant Support has a weak but positive correlation with Cost of Living $(r h o=.149, p=.038)$. However, regression analysis indicates no statistically significant contribution of Cost of Living to Participant Support. Other demographic variables, including gender, did not have statistically significant relationships with Participant Support. This result was quite intriguing to me, since I expected to see gender differences. In general, women are often considered more caring and supportive than men. The results show, however, male participants perceive 
themselves to be providing emotional support to their friends as much as female participants perceive. Although these perceptions may not match with the actual behavior, the result indicates no difference in providing emotional support between males and females.

\section{Relationship between Investing and Vesting Expressive Resources}

Research Question 3 probed the relationship between "investing” and "vesting” expressive resources. The study shows that the strongest correlation among variables is the one between Participant Support and Friends Support $(r=.539, p=.000)$. That is, an individual who provides more support to his or her friends is more likely to receive emotional support from friends. I could not find literature focusing on the

relationship between investing and vesting in the communication field, so this finding is noteworthy. Social capital research in communication often examines "what an individual does for others" such as working as a volunteer and helping neighbors, but rarely focuses on "what others do for an individual." This study reveals that there is a positive correlation between providing and receiving emotional support. 
Social capital is a vague cyclical process and its communicative process is difficult to examine since people are often unaware of the process of investing and vesting, especially since expressive resources are invisible and not easily quantifiable. Most people are not mindful about "investing my emotional support” when they listen to their friends lamenting; similarly, people do not think about "getting my share back" when they seek a shoulder to cry on. Actual giving and receiving may not occur simultaneously, and the return of the investment is not always guaranteed. Molm (2010) found in her reciprocal exchange research that people "perform individual acts that benefit another, like giving help or advice, without negotiation and without knowing whether or when the other will reciprocate” (pp. 119-120). Still, the correlation between Participant Support and Friends Support suggests that people experience both providing and receiving emotional support and the amount of investing and vesting seems to be proportional. That is, people are following a tacit rule of reciprocity while giving and receiving emotional support.

Because of the nature and mutuality of social capital, the process of emotional support does not have a clear cause and effect. Once you help your friends, your friends are more likely to help you. Then, your investment toward the friendship will 
be even more enhanced since you know that you will get a return. Such reciprocity will be enhanced each time when friends and an individual exchange emotional support; you are now in the virtue circle of friendship.

Furthermore, expressive resources which an individual invests seem to come back to the person in the form of expressive resources—not in other forms of

resources (e.g. money, job references). That is, when people get emotional support from their friends, they seem to return the favor in the form of emotional support. Lin (2001) asserted that social capital promotes two kinds of actions: expressive and instrumental. The current study suggests that expressive action will be rewarded by expressive ation.

\section{Gap between Investing and Vesting Expressive Resources}

Although Participant Support and Friends Support are correlated, the degree of support is not equal. Paired sample t-test shows that Participant Support scores $(M=$ 49.60, $S D=6.25)$ are significantly higher than Friends Support scores $(M=45.66, S D$ $=8.10)(t=-7.737, d f=193, p=.000)$. That is, participants perceive that they are 
investing more expressive resources (giving emotional support) than vesting

(receiving emotional support).

The current study identifies the gap, but does not explain why or how the gap is created. My supposition is that people are less aware of receiving emotional support compared with providing it to others. Providing emotional support (e.g., listening to your friends and giving advice) is conscious and mindful behavior; in contrast, people may not always notice what their friends are doing for them. People tend to notice and remember what they did to others more than what others did for them. However, to test my supposition, future study will be needed.

Furthermore, the post-hoc analysis reveals that the gap may vary depending on the participant's cultural or ethnic background; the gap between two social capital scales is statistically significant among students from Saudi Arabia and India while the gap is not significant for Korean, Chinese and Japanese students. Since the current study does not have large enough samples for other countries, I could not conduct further statistical analyses. However, I would argue that there are two potential interpretations of this difference. One, these East Asian (Korean, Chinese, and Japanese) students receive emotional support as much as they provide; not like Saudi 
Arabian and Indian students who perceived that they provide more than they receive.

The other possibility is that East Asian students tweaked their perception in order to

"match up" the balance. As one of my friends said that it was difficult for him to choose "strongly agree" for helping friends, East Asian students might have

— consciously or unconsciously—underrated their own effort to provide emotional

support. Either way, the results implies that cultural aspects might be one of the effects

of the gap (or lack of gap) between the two types of support.

\section{Socializing with Friends and Social Capital}

A number of social capital research asserted that concrete social interactions

with others are important element of social capital because social capital concerns

resources embedded in one's social relationship. Research Question 4a and 4b asked if

informal social interaction with friends, such as eating meals and studying together,

influences the degree to which participants receive emotional support (Friends

Support) and give emotional support (Participant Support).

Socializing with Friends has statistically significant positive correlations both

Friends Support $(r=.360, p<.01)$ and Participant Support $(r=.338, p<.01)$. As 
students hang out with friends more often, they provide and receive more emotional support to and from friends. On the other hand, an individual who does not socialize with friends often is less likely to exchange emotional support with their friends. While most of the other demographic variables and personal attributes do not have statistically significant relationships with both Participant and Friends Support, Socializing with Friends seems to play a key role in the process.

Socializing with Friends also has a statistically significant positive correlation with Life Satisfaction $(r=.209, p<.01)$. That is, an individual who socializes more with his or her friends is more likely to show a higher satisfaction with his or her school life.

Besides Friends Support, Participant Support, and Life Satisfaction, what else influences Socializing with Friends? Interestingly, the results show that only Length of Residency at PSU has a statistically significant correlation with Socializing with Friends. In other words, other personal attributes, such as gender or age, Language (Comfort level in English, English Proficiency, and being native English speakers), or financial conditions (Cost of Living and Affluence) do not seem to matter for the degree of informal social interaction with friends. I could not identify what else effects 
Socializing with Friends besides Length of Residency at PSU. That implies there

might be something I did not measure in the study. For example, I did not include

"trust,” which is often used in social capital research. Moreover, there might be

potential that other personality traits (e.g., social identity) affect the degree of informal

social interaction.

\section{Life Satisfaction and Social Capital}

Another key element in social capital is satisfaction with life. Lin (2001) stated that expressive action (vesting expressive resource) in the social capital process will provide life satisfaction as a return. I also wanted to see if the investing behavior (i.e., providing emotional support) also brings life satisfaction to an individual. Research Question 5a and 5b concerned the relationships between social capital and life satisfaction at Portland State University. For the current study, I treated Life Satisfaction as a dependent variable of social capital.

The study shows that Life Satisfaction is positively correlated with Friends

Support $(r=.149, p<.05)$, but there is no statistically significant positive relationship with Participant Support $(r=.079, \mathrm{p}=.271)$. This means that receiving emotional 
support from friends is more likely to bring higher Life Satisfaction to an individual.

On the other hand, providing emotional support for friends does not have a significant impact on Life Satisfaction.

Socializing with Friends also has a statistically significant positive correlation with Life Satisfaction $(r=.209, p<.01)$. Life Satisfaction also has a weak but positive correlation with Number of Housemates $(r=.150, p<.05)$; independent sample t-tests also indicate the means of Life Satisfaction of participants living with someone ( $n=$ $153, M=16.35, S D=4.28$ ) are notably higher than the Life Satisfaction of participants who are living alone $(n=41, M=14.32, S D=3.47)(t=-2.805, d f=192$, $p=.006$ ). When an individual is living with someone, he or she is more likely to be satisfied with their college life; furthermore, more housemates means more life satisfaction.

Number of housemates implies another form of informal social interaction. When you are living with someone, you are bound to have some kind of interaction with them. You may cook, eat, watch TV, and chat. The results implied that such informal interactions with people (Socializing with Friends and Number of Housemates) bring satisfaction to an individual. It also means that a higher degree of 
Life Satisfaction may not always be related to the degree of vesting expressive resources (Friends Support). Life Satisfaction seems to be caused by many other elements as well.

\section{Contributions to the Body of Literature}

The current study has three significant contributions to the body of literature in the communication field. First, the study focused on measuring the communicative aspects of the social capital process. Two sides of the social capital process, investing and vesting expressive resources, were measured by the communication-based emotional support scales. The results suggest that this bidirectional measurement seems to have sufficient validity. Second, the current study revealed that investing and vesting expressing resources seems to be balanced although individuals in general tend to perceive that they provide for their friends more than they receive. This finding suggests that a tacit rule of reciprocity seems to exist; when people help others, their efforts seem to be rewarded. Third, by focusing on the communicative aspect of the social capital process, the study identified that informal social interaction, such as studying together and eating meals, seems to be an important aspect that enriches 
one's social capital. Informal social interaction itself is communication between individuals. In other words, communication with friends influences one's active emotional support exchange.

\section{Perceived Expressive Resources}

The current study measured how the participants perceived their investing and vesting expressive resources, but not the actual expressive resources exchanged. The Communication Based Emotional Support Scale does not ask what the participants did for their friends or vice versa. Instead, the scale measures how participants estimate support from friends. Then, I should assume that there must be a gap between their perception and actual behaviors. We all experienced times when our friends did not help us when we were in trouble and needed help. On the other hand, sometimes an unfriendly person turns out to be a loyal friend in a crisis. We cannot guarantee how an individual will behave in a real situation. We can only speculate. The current study indicates a positive and significant correlation between investing and vesting expressive resources in perception, but this result does not guarantee that there is correlation between the actual behaviors of giving and receiving emotional support. 
I argue that perceived resources are as important as the actual resource for an individual's psychological well-being. Even though the emotional support the participant addressed in the survey is mere perception, it provides a sense of social capital. The participant can count on his or her friends' help. Without a feeling of "my friends would help me when I am in trouble,” we will have a miserable, frightening, and isolated life.

\section{Implications of the Current Study to International Students}

The current study examined how international students provided and received emotional support to and from their friends. The amount of providing and receiving emotional support are correlated, and frequency of socializing with friends predicts these two behaviors. The current study suggests that social interaction with friends has a small but statistically significant impact for international students to enrich their social capital. However, I imagine that finding an opportunity to socialize with others may be difficult for some students in an unfamiliar culture. One suggestion I can draw from my research is that universities can promote international student socialization in order to assist them to establish their new social capital. For example, universities can 
provide spaces (e.g., group study room) and information (news for school events) so students can easily meet and mingle with each other.

In order to understand emotional support exchange by international students, further research will be needed. For example, the current study did not examine the quality of friend groups. Are friends from the same country? Are they international students from other countries? American students? Or a mix of these? Examining the composition of friendships will help us to understand why some students exchange emotional support more than others. Also, the study lacks a control group (e.g., American students). Are there any differences in emotional support exchanges by international students and American students? The study did not answer this question. The results instead suggest a dissimilar pattern of providing and receiving emotional support by East Asian students. This finding suggests that there might be a cultural influence on perceived emotional support exchange. Further research will help to understand both social capital and international students. 


\title{
Inconsistency of Communication Based Emotional Support Scales
}

\author{
Although the convergent validity of the scale was demonstrated in the past \\ studies, the findings indicate that there are some inconsistencies and differences in \\ both scales.
}

Differences in Friends Support scale. Although students acknowledge receiving emotional support from their friends, they rated two behaviors lower than others. The two items are: "My PSU friends help me understand my thoughts and feelings about major life decisions (For example, career choice)” and “My PSU friends help me deal with problems concerning other friends and/or family members.” When I took a close look at these two items, I realized these two behaviors seem to require more commitment and more effort than other behaviors such as “pay attention” and "listen my side of story." In other words, paying attention or listening is easier than helping others to understand thoughts and feelings or to deal with problems. The "helping” action also seems to take a longer time than "listening” or "paying attention.” As I stated in the results section, all 13 items in Friends Support have high internal consistency $(\alpha=.903)$. However, the results of differences depending on behaviors imply that there might be differences in the level of behaviors in the scale. 
Differences in Participant Support scale. A large percentage of participants

(66-90\%) perceived that they provide emotional support to their friends except two items: item 5, "I avoid my PSU friends when they are upset" and item 8, "When my PSU friends want to talk to me, I seem to have something else to do.” The direction was reversed in these two items, so participants were expected to disagree with the sentence in order to be consistent with other items. However, many participants agreed that they do avoid their friends and have something else to do.

This inconsistency of the responses could be caused by the confusion of reversed direction, but I would argue that these different responses are based on the participants' honest feelings. When I think about my own experience, helping friends sometimes takes lots of time and energy. "Avoiding friends" and "having something else to do" do not contradict other items such as "saying and doing supportive things." People want to help others and they actually do so, but at the same time, they may want to avoid friends and do something else. These two feelings can exist without excluding each other. 
The reliability analysis showed that the 13 items share high internal consistency $(\alpha=.850)$ even with the confusion of wording, but the scale may be improved if the researcher rephrased the items.

\section{Limitations and Future Prospects}

One limitation of the study is its generalizability. The response rate for the current study was relatively low (12.7\%) and the population of the study is only 194 . Also, the population of the study consists of foreign university students. Although I would argue that the fundamental process of investing and vesting social capital would be the same in any population, it is difficult to generalize the results of the study. Replication of the study for different populations will be beneficial in obtaining a better understanding of the investing and vesting process.

The study examined international students and did not have a control group (non-international students). Although cultural influence should be minimized by integrating the results of all of the international students, American students, who should have more complex and developed social capital in the United States, might respond to the questions differently. I imagine that there are two opposite forces 
influencing American students. Since American students already have a rich

friendship and network outside of the university, they may not value friendship within the university as greatly as international students. In contrast, they might value friendship higher than international students since they are bound to the country and culture, compared to the international student who may leave this country after graduation. Future study examining American students will reveal which element has a stronger influence.

Also, to control the conditions of the research, the current study only focuses on friendship among PSU students, and ignores other options including friendship in their home countries, in the online world, or in their "outside of college" network (e.g., volunteering). Some students may have meager friendships at PSU while they actually have a rich and fruitful social life with their Facebook friends. Friendship in their home country will change over time depending on how often the student can contact (visit, call, or write) their friends back home. Frequency of contact will likely be determined by affluence as well as level of technology in their country and proximity. Some students can easily access their home country (e.g., there is a direct flight from Portland to Japan and Germany), while other students cannot (they have many 
connecting flights before they reach home). If a student is from a developing country, it may not easy to use the internet to place a telephone call which is often free of charge; the student has to pay a fee for the international call, so he or she may not call their friends as often as those whom can talk with their friends via Internet call. Such closeness to social capital in his or her home country may influence the student's social capital in the U.S. Future studies need to explore various friendships in other social settings.

The Communication Based Emotional Support Scale (CBESS) has also its limitations. Although CBESS is a well-established scale, it only measures emotional support when an individual is in some kind of crisis (i.e., upset or depressed). After conducting the survey, I realized that the emotional support I measured in the current study may be limited to the time people are experiencing difficulties. Emotional support is "expressions of concern, compassion, sympathy, and esteem for another individual” (Weber \& Patterson, 1996, p.69). In that sense, celebrating for special occasions, giving a compliment, or showing appreciation to others can be good emotional support, but the CBESS cannot capture such non-crisis emotional support. Future study should consider different kind of emotional support among friends. 


\section{Conclusion}

In conclusion, the current study explored the relationship between providing and receiving emotional support, and found a statistically significant correlation between the two perceived behaviors. The study also found that the frequency of informal social interaction predicts both behaviors. Personal attributes, however, did not have a statistically significant impact on either behavior. The study contains much potential to expand the research in many directions in order to gain more understanding in social capital. 


\section{References}

Aubrey, J. S., Rill, A. L., \& Chattopadhyay, S. (May, 2008). Are Facebook friends

like face-to-face friends? Investigating relations between the use of social networking websites and social capital. Paper presented at the annual meeting of the International Communication Association, Montreal, Quebec, Canada. Retrieved from http://www.allacademic.com/meta/p232185_index.html

Babbie, E. (2004). The practice of social research $\left(10^{\text {th }}\right.$ ed.). Belmont, CA: Wadsworth.

Beaudoin, C. E. \& Thorson, E. (2004). Social capital in rural and urban communities: Testing differences in media effects and models. Journalism and Mass Communication Quarterly, 31(2), 378-399.

Beaudoin, C. E. \& Thorson, E. (2006). The social capital of Blacks and Whites: Differing effects of the mass media in the United States. Human Communication Research, 32, 157-177.

Beaudoin, C. E. (2007). Mass media use, neighborliness, and social capital: Assessing causal links with panel data. Communication Research, 34(6), 637-664. 
Beaudoin, C. E. (2008). Explaining the relationship between Internet use and interpersonal trust: Taking into account motivation and information overload. Journal of Computer-Mediated Communication, 13, 550-568.

Bourdieu, P. (1986). The forms of capital. In Richardson, J. G. (Eds.) Handbook of Theory and Research of the Sociology of Education. (pp.241-258). New York: Greenwood Press.

Chaffee, S. H. (1991). Communication concepts 1: Explication. Newbury Park, CA: Sage.

Coleman, J. S. (1990). Foundations of social theory. Massachusetts: Belknap Press and Harvard University Press.

Diener, E., Emmons, R.A., Larsen, R.J., \& Griffin, S. (1985). The satisfaction with life scale. Journal of Personality Assessment, 49, 71-75.

Ellison, N. B., Steinfield, C., \& Lampe, C. (2007). The benefits of Facebook “friends:” Social capital and college students' use of online social network sites. Journal of Computer-Mediated Journal, 12(4), Retrieved from http://jcmc.indiana.edu/vol12/issuet/ellison.html. 
Educational Testing Service

http://www.ets.org/Media/Tests/TOEFL/pdf/TOEFL_iBT_Score_Comparison_T

ables.pdf

Fleming, K., Thorson, E., \& Peng, Z. (2005). Associational membership as a source of social capital: Its links to use of local newspaper, interpersonal communication, entertainment media, and volunteering. Mass Communication \& Society, 8(3), 219-240.

Hanifan, L. J. (1916). The rural school community center. In Suhrie, A. L. (Eds.), New possibilities in education. Philadelphia; the American academy of political and social science.

Ikeda, K. (2002). Social capital and social communication in Japan: Political participation and tolerance. Center for the Study of Democracy, 02-05. Retrieved from http://repositories.cdlib.org/csd/02-05

Kao, G. (2004). Social capital and its relevance to minority and immigrant populations. Sociology of Education, 77(2), 172-175. 
Kao, G. \& Rutherford, L. T. (2007). Does social capital still matter? immigrant minority disadvantage in school-specific social capital and its effects on academic achievement. Sociological Perspectives,50(1),27-52.

Kikuchi, M. \& Coleman, C. L. (2008). Explicating and measuring social relationships in social capital research: A working paper. Paper presented at the annual meeting of the Association for Education in Journalism and Mass Communication, Chicago, IL, Retrieved from http://www.allacademic.com/meta/p271799_index.html

Ley, B. (2007). Vive les roses!: The architecture of commitment in an online pregnancy and mothering group. Journal of Computer-Mediated Communication, 12(4), article 12. Retrieved from http://jcmc.indiana.edu/vol12/issue4/ley.html

Lee, GH., Cappella, J. N., \& Southwell, B. (2003). The effects of news and entertainment on interpersonal trust: Political talk radio, newspapers, and television. Mass Communication \& Society, 6(4), 413-434.

Lin, N. (2001). Social capital: A theory of social structure and action. Cambridge, UK: Cambridge University Press. 
Lin, N. \& Dumin, M. (1986). Access to occupations through social ties. Social

Networks. 8. 365-385.

Lowrey, W. (2004). Media dependency during a large scale social disruption: The case of September 11. Mass Communication \& Society, 7(3), 339-357.

Maundeni, T. (2001). The role of social networks in the adjustment of African students to British society: students’ perceptions. Race Ethnicity and Education, 4, 253-276.

McLeod, J. M. \& Chaffee, S. R. (1972). The construction of social reality. In J. R. Tedeschi (Ed), The Social Influence Process, (pp.50-99). Aldine, Atherton.

Molm, L. D. (2010). The structure of reciprocity. Social Psychology Quarterly. 73(2). 119-131.

Mortenson, S. T. (2006). Cultural differences and similarities in seeking social support as a response to academic failure: A comparison of American and Chinese college students. Communication Education, 55(2), 127-146.

Moy, P., Scheufele, D. A., \& Holbert, R. L. (1999). Television use and social capital: Testing Putnam's time displacement hypothesis. Mass Communication \& Society, 2(1/2), 27-45. 
Mueller, R. E. (2009). Does the statue of liberty still face out? The diversion of foreign students from the United States to Canada in the post 9/11 period. Canadian Journal of Higher Education. 39(1). 15-43.

The Office of Institutional Research and Planning. (2010).

Winter Term Factbook 2010 (4th Week), retrieved from http://www.oirp.pdx.edu/source/fact10w/factw104.htm

Putnam, R. D. (1995a). Bowling alone: America’s declining social capital. Journal of Democracy, 6(1), 65-78.

Putnam, R. D. (1995b). Tuning in, tuning out: The strange disappearance of social capital in America. PS: Political Science and Politics, 28(4), 664-683.

Putnam, R. D. (2000). Bowling alone: The collapse and revival of American Community. New York: Harper Collins.

Rittenour, C. E. \& Martin, M. M. (2008). Convergent validity of the communication based emotional support scale. Communication Studies, 59(3), 235-241.

Scheufele, D. A. \& Shah, D. V. (2000). Personality strength: the role of dispositional and informational variables in the production of civic participation. Communication research, 27(2), 107-131. 
Siringi, S. \& Franey, L. (2008, April 27). Post-Sept. 11 requirements put squeeze on colleges. The Kansas City Star.

Shah, D. V. (1998). Civic engagement, interpersonal trust, and television use: An individual-level assessment of social capital. Political Psychology. 19(3), Special Issue: Psychological Approaches to social capital, 469-496.

Shah, D. V., Cho, J., Eveland, Jr. W. P., \& Kwak, N. (2005). Information and expression in a digital age: Modeling internet effects on civic participation. Communication Research, 32(5), 531-565.

Shah, D. V., Kwak, N., \& Holbert, R. L. (2001). "Connecting" and "disconnecting" with civic life: Patterns of internet use and the production of social capital. Political Communication, 18(2), 141-162.

Shah, D. V., McLeod, J. M., \& Yoon, S. H. (2001). Communication, context, and community: An exploration of print, broadcast, and internet influences. Communication Research, 28(4), 464.

Shah, D., Schmierbach, M., Hawkins, J., Espino, R., \& Donavan, J. (2002). Nonrecursive models of Internet use and community engagement: questioning 
whether time spent online erodes social capital. Journalism \& Mass

Communication Quarterly, 79(4), 964-987.

Thorson, E. \& Beaudoin, C. E. (2004). The impact of a health campaign on health social capital. Journalism of Health Communication, 9, 167-194

TOEIC TOEFL Score Conversion Table (2010)

Retrieved on May 25, 2010 from

http://allabout.co.jp/study/toeic/closeup/CU20040710A/index2.htm

Uslaner, E. M. (2004). Trust, civic engagement, and the Internet. Political

Communication, 21, 223-242.

Weber, K. D. \& Patterson, B. R. (1996). Construction and validation of a communication based emotional support scale. Communication Research Reports, 13(1), 68-76.

Wellman, B. \& Frank, K. (2001). Network capital in a multi-level world: Getting support from personal communities. In N. Lin, K. Cook, \& R. S. Burt, (Eds.), Social capital: Theory and research (pp. 233-273). Rutgers, NJ: Aldine Transaction. 
Williams, D. (2006). On and off the 'Net': Scales for social capital in an online era. Journal of Computer-Mediated Communication, 11, 593-628.

Williams, D. (2007). The impact of time online: Social capital and cyberbalkanization. Cyber Psychology \& Behavior, 10(3), 398-406.

Yuan, Y. C. \& Gay, G. (2006). Homophily of network ties and bonding and bridging social capital in computer-mediated distributed terms. Journal of Computer-Mediated Communication, 11, 1062-1084.

Zhang, W. \& Chia, S. C. (2006). The effects of mass media use and social capital on civic and political participation. Communication Studies, 57(3), 277-297. 


\section{APPENDIX A: Approval of Human Subject Application}

Portland State

Human Subjects Research Review Committee

$\begin{array}{ll}\text { Post Office Box } 751 & 503-725-4288 \text { tel } \\ \text { Portland, Oregon 97207-0751 } & 503-725-3416 \text { fax } \\ & \text { hsrrc@lists.pdx.edu }\end{array}$

February 1, 2010

To: Mami Kikuchi

From: Nancy Koroloff, HSRRC Chair Thuney toroliffles

Re: Approval of your application titled, "Investing and Vesting Expressive Resources in Social Capital by International Students at Portland State University" (HSRRC Proposal \# 091129).

Dear Mami,

In accordance with your request, the Human Subjects Research Review Committee has reviewed your proposal referenced above for compliance with DHHS policies and regulations covering the protection of human subjects. The committee is satisfied that your provisions for protecting the rights and welfare of all subjects participating in the research are adequate, and your project is approved. Please note the following requirements:

Changes to Protocol: Any changes in the proposed study, whether to procedures, survey instruments, consent forms or cover letters, must be outlined and submitted to the Chair of the HSRRC immediately. The proposed changes cannot be implemented before they have been reviewed and approved by the Committee.

Continuing Review: This approval will expire on February 1, 2011. It is the investigator's responsibility to ensure that a Continuing Review Report (available in ORSP) of the status of the project is submitted to the HSRRC two months before the expiration date, and that approval of the study is kept current.

Adverse Reactions: If any adverse reactions occur as a result of this study, you are required to notify the Chair of the HSRRC immediately. If the problem is serious, approval may be withdrawn pending an investigation by the Committee.

Completion of Study: Please notify the Chair of the Human Subjects Research Review Committee (campus mail code ORSP) as soon as your research has been completed. Study records, including protocols and signed consent forms for each participant, must be kept by the investigator in a secure location for three years following completion of the study.

If you have questions or concerns, please contact the HSRRC in the Office of Research and Sponsored Projects (ORSP), (503) 725-4288, 6th Floor, Unitus Building, 4th \& Lincoln.

Cc: Cynthia-Lou Coleman 


\section{Survey for International Students-Win a \$25 gift certificate to the PSU bookstore!}

Dear fellow students,

I know you are busy getting ready for finals, but I have a favor to ask.

My name is Mami Kikuchi. I am a Master’s student in the Department of Communication at PSU. I am trying to understand international students and their friendships for my thesis. To do so, I need your help in getting my survey completed. Could you please give me 10 minutes of your time to fill out the survey?

Your participation will contribute to a better understanding about international students at PSU and my graduation is in your hands!

To show my appreciation, I bought four \$25 gift certificates for the PSU bookstore (you can use it to buy textbooks, snacks, stationery, etc). You have the chance to join the random drawing after completing the survey.

Your response will be anonymous; in other words, we will not ask your name and all responses will be kept completely confidential.

Here is the link to my survey. $<<<$ link to the survey $>>>>$

If this link does not work, please copy the following URL and paste it into your browser:

$<<<$ link to the survey $>>>$

Thank you in advance. I really appreciate your help and input.

Have a great day! 
Mami Kikuchi

If you have questions or comments, please contact with me at mami@pdx.edu.

Mami Kikuchi

Department of Communication,

23 Neuberger Hall

Portland State University

P.O. Box 751

Portland, OR 97201

503.725 .5367 


\section{Survey for International Students-Win a \$25 gift certificate to the PSU bookstore!}

Dear fellow students,

Thank you for participating in my study on international students and friendship. I really appreciate that so many students took time for me to complete the survey. Your contribution means a lot for me and for better understanding about international students at PSU.

If you have not participated in my research yet, please take 10 minutes of your time to fill out the survey. Your responses will be kept completely confidential. Don't miss the chance to win $\$ 25$ gift certificate for PSU bookstore!

Here is the link to my survey. http://survey.oit.pdx.edu/ss/wsb.dll/s/2bfg1242

If this link does not work, please copy the following URL and paste it into your browser:

http://survey.oit.pdx.edu/ss/wsb.dll/s/2bfg1242

Thank you in advance. I really appreciate your help and input.

Have a great day!

Mami Kikuchi

If you have questions or comments, please contact with me at mami@pdx.edu.

Mami Kikuchi

Department of Communication, 23 Neuberger Hall 
Portland State University

P.O. Box 751

Portland, OR 97201

503.725.5367 
APPENDIX D: Survey for Friendship of International Students

\section{Informed Consent}

You have been invited to participate in a research project by Mami Kikuchi, a Master's candidate in the Department of Communication at Portland State University. This study explores the friendship of international students. As an international student, you were selected as a participant in this study.

Your participation is completely voluntary and will have no influence on your grades or academic standing at Portland State and the Department of Communication. You may stop taking the survey at any time. Again, such a move will not affect your grades or academic standing.

If you decide to participate, you will be asked to complete a brief online survey. The purpose of this survey is to collect data relating to friendship.

Your response will be anonymous; in other words, we will not ask your name. You will have the chance to win a $\$ 25$ gift card for The PSU bookstore (you can use it to buy textbooks, snacks, stationery, etc), but will not receive any direct benefit from taking part in this survey. The results of the survey, however, may assist in increasing knowledge about friendships. The survey should take between 10 to 15 minutes to complete.

If you wish to enter the lottery for the gift card, you will be asked to provide your e-mail address at the end of the survey. However, your e-mail address will not be connected with the survey and you do not have to provide your name. You can participate in the survey and the lottery only one time. If you win the lottery, the Communication Department Office will send a notification to your e-mail address within one month.

If you have any concerns or problems about your participation in this study, or if you have questions about your rights as a research subject, please contact: 
Human Subjects Research Review Committee, Office of Research and Sponsored Projects

600 Unitus Building (2121 SW 4th Avenue) Portland State University

Phone: 503.725.3423 or 800.547.8887 E-Mail: orsp@pdx.edu

http://www.rsp.pdx.edu/research.php

If you have questions about the study itself, contact:

Mami Kikuchi

23 Neuberger Hall, Portland State University, Phone: 503.725.5368,

E-mail: $\underline{\text { mami@pdx.edu }}$

Since the survey is about friendship, it may make you emotional; you may miss your friends in your home country. A counseling service is available at the Center for Student Health and Counseling at 503.725.2800. Students who are full time or part time and have paid the health fee are eligible to see a social worker, psychologist, or psychiatrist at no charge.

By checking yes, you indicate that you have read and understood the above information and agree to take part in this study. Please be aware that you may withdraw your consent at any time without penalty. By checking yes, you are not waiving any legal claims, rights or remedies. The researcher will provide you with a copy of this form upon request.

\section{1) I agree with the terms:}

$\square$ Yes

$\square$ No 
Thank you for participating in this survey. Your participation will help us to gain better understanding about international students.

This is not a test! There is no right or wrong answer. You can use a dictionary if necessary. It will take 10 to 15 minutes to complete the survey.

Important: when you answer questions, please answer by yourself (do not consult with your friends).

Before you start answering the survey, please think about your friends at Portland State University (Let's call them your PSU friends).

PSU friends include any kinds of students you meet at PSU (full-time, part-time, undergraduate, graduate, international, American, etc).

2) How many times did you do the following activities with your PSU friends over the last 2 weeks? (activities can take place both at PSU and outside of PSU)

\begin{tabular}{|l|c|c|c|c|c|c|}
\hline & Never & $\begin{array}{c}1-3 \\
\text { times }\end{array}$ & $\begin{array}{c}4-6 \\
\text { times }\end{array}$ & $\begin{array}{c}7-9 \\
\text { times }\end{array}$ & $\begin{array}{c}\text { 10-12 } \\
\text { times }\end{array}$ & $\begin{array}{c}\text { More } \\
\text { than 13 } \\
\text { times }\end{array}$ \\
\hline Studied with my PSU friends & $\square$ & $\square$ & $\square$ & $\square$ & $\square$ & $\square$ \\
\hline Ate a meal with my PSU friends & $\square$ & $\square$ & $\square$ & $\square$ & $\square$ & $\square$ \\
\hline $\begin{array}{l}\text { Went to a restaurant or coffee shop with my PSU } \\
\text { friends }\end{array}$ & $\square$ & $\square$ & $\square$ & $\square$ & $\square$ & $\square$ \\
\hline $\begin{array}{l}\text { Went to a university-related event (e.g. sporting } \\
\text { event, play) with my PSU friends }\end{array}$ & $\square$ & $\square$ & $\square$ & $\square$ & $\square$ & $\square$ \\
\hline Watched TV with my PSU friends & $\square$ & $\square$ & $\square$ & $\square$ & $\square$ & $\square$ \\
\hline Hosted a social gathering & $\square$ & $\square$ & $\square$ & $\square$ & $\square$ & $\square$ \\
\hline Went to a party or a bar with my PSU friends & $\square$ & $\square$ & $\square$ & $\square$ & $\square$ & $\square$ \\
\hline Engaged in other activities with my PSU friends & $\square$ & $\square$ & $\square$ & $\square$ & $\square$ & $\square$ \\
\hline
\end{tabular}


Next, I'd like you to think about communication with your PSU friends. For each statement, please respond by clicking the button that best represents your agreement with that statement.

\begin{tabular}{|c|c|c|c|c|c|}
\hline & $\begin{array}{c}\text { Strongly } \\
\text { Disagree } \\
1\end{array}$ & $\begin{array}{c}\text { Disagree } \\
2\end{array}$ & $\begin{array}{c}\text { Not Sure } \\
3\end{array}$ & $\begin{array}{c}\text { Agree } \\
4\end{array}$ & $\begin{array}{c}\text { Strongly } \\
\text { Agree } \\
5\end{array}$ \\
\hline $\begin{array}{l}\text { My PSU friends help me understand my thoughts } \\
\text { and feelings about major life decisions (For } \\
\text { example, career choice) }\end{array}$ & $\square$ & $\mathbf{L}^{-1}$ & $\square$ & $\square$ & $\square$ \\
\hline $\begin{array}{l}\text { My PSU friends patiently and sensitively listen to } \\
\text { me complain about a problem that I am having }\end{array}$ & & & - & [ & $\mathbf{L}^{-1}$ \\
\hline $\begin{array}{l}\text { When I tell my PSU friends about a problem that I } \\
\text { am having, they pay attention }\end{array}$ & 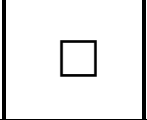 & $\square$ & \begin{tabular}{|c} 
\\
\end{tabular} & 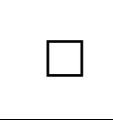 & $\square$ \\
\hline $\begin{array}{l}\text { My PSU friends help me deal with problems } \\
\text { concerning other friends and/or family members }\end{array}$ & & & 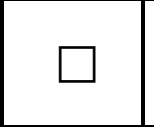 & [ & - \\
\hline My PSU friends avoid me when I am upset & $\square$ & $\square$ & $\square$ & $\square$ & $\square$ \\
\hline My PSU friends are good listeners when I am upset & $\square$ & $\square$ & $\square$ & $\square$ & $\square$ \\
\hline $\begin{array}{l}\text { My PSU friends say and do supportive things for } \\
\text { me when I am feeling down }\end{array}$ & & & L & 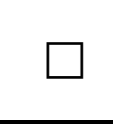 & - \\
\hline $\begin{array}{l}\text { When I want to talk to my PSU friends about what } \\
\text { is bothering me, they seem to have something else } \\
\text { to do }\end{array}$ & $\square$ & & $\square$ & & $\square$ \\
\hline $\begin{array}{l}\text { My PSU friends show honest concern for my } \\
\text { problems }\end{array}$ & L & & $\square$ & $\Gamma$ & L \\
\hline $\begin{array}{l}\text { My PSU friends give me good advice when I ask } \\
\text { for it }\end{array}$ & & & & & 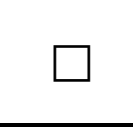 \\
\hline $\begin{array}{l}\text { My PSU friends make it very easy to discuss my } \\
\text { personal feelings }\end{array}$ & L & 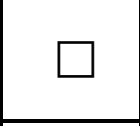 & $\square$ & $\Gamma$ & 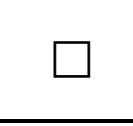 \\
\hline $\begin{array}{l}\text { My PSU friends listen to my side of the story even } \\
\text { if they think that I am wrong }\end{array}$ & L & - & $\square$ & $\square$ & - \\
\hline $\begin{array}{l}\text { My PSU friends make an effort to make me feel } \\
\text { better when I am depressed }\end{array}$ & L & L & $\square$ & L & $\mathbf{S}^{-1}$ \\
\hline
\end{tabular}


Now, I'd like you to tell me about your life at PSU.

For each statement, please respond by clicking the button that best represents your agreement with that statement.

\begin{tabular}{|l|c|c|c|c|c|}
\hline & $\begin{array}{c}\text { Strongly } \\
\text { Disagree } \\
1\end{array}$ & $\begin{array}{c}\text { Disagree } \\
2\end{array}$ & $\begin{array}{c}\text { Not Sure } \\
3\end{array}$ & $\begin{array}{c}\text { Agree } \\
4\end{array}$ & $\begin{array}{c}\text { Strongly } \\
\text { Agree } \\
5\end{array}$ \\
\hline $\begin{array}{l}\text { In most ways my life at Portland State } \\
\text { University (PSU) is close to my ideal }\end{array}$ & $\square$ & $\square$ & $\square$ & $\square$ & $\square$ \\
\hline The conditions of my life at PSU are excellent & $\square$ & $\square$ & $\square$ & $\square$ & $\square$ \\
\hline I am satisfied with my life at PSU & $\square$ & $\square$ & $\square$ & $\square$ & $\square$ \\
\hline $\begin{array}{l}\text { So far I have gotten the important things I want } \\
\text { at PSU }\end{array}$ & $\square$ & $\square$ & $\square$ & $\square$ & $\square$ \\
\hline $\begin{array}{l}\text { If I could re-live my time at PSU, I } \\
\text { would not change anything }\end{array}$ & $\square$ & $\square$ & $\square$ & $\square$ & $\square$ \\
\hline
\end{tabular}


Think about your PSU friends one more time, and read the following statements.

For each statement, please respond by clicking the button that best represents your agreement with that statement.

\begin{tabular}{|c|c|c|c|c|c|}
\hline & $\begin{array}{c}\text { Strongly } \\
\text { Disagree } \\
1\end{array}$ & $\begin{array}{c}\text { Disagree } \\
2\end{array}$ & $\begin{array}{c}\text { Not Sure } \\
3\end{array}$ & $\begin{array}{c}\text { Agree } \\
4\end{array}$ & $\begin{array}{c}\text { Strongly } \\
\text { Agree } \\
5\end{array}$ \\
\hline $\begin{array}{l}\text { I help my PSU friends understand their thoughts and } \\
\text { feelings about major life decisions (e.g. career } \\
\text { choice) }\end{array}$ & $\square$ & [ & ए & $\square$ & $\square$ \\
\hline $\begin{array}{l}\text { I patiently and sensitively listen to my PSU friends } \\
\text { complain about a problem that they are having }\end{array}$ & 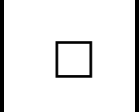 & L & - & $\square$ & L \\
\hline $\begin{array}{l}\text { When my PSU friends tell me about a problem that } \\
\text { they are having, I pay attention }\end{array}$ & $\square$ & L & \begin{tabular}{|c} 
\\
\end{tabular} & $\square$ & $\square$ \\
\hline $\begin{array}{l}\text { I help my PSU friends deal with problems concerning } \\
\text { other friends and/or family members }\end{array}$ & 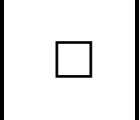 & L & - & $\square$ & ए \\
\hline I avoid my PSU friends when they are upset & $\square$ & $\square$ & $\square$ & $\square$ & $\square$ \\
\hline I am a good listener when my PSU friends are upset & $\square$ & $\square$ & $\square$ & $\square$ & $\square$ \\
\hline $\begin{array}{l}\text { I say and do supportive things for my PSU friends } \\
\text { when they are feeling down }\end{array}$ & L & L & $\mathbf{S}^{-1}$ & $\square$ & L \\
\hline $\begin{array}{l}\text { When my PSU friends want to talk to me about what } \\
\text { is bothering them, I seem to have something else to do }\end{array}$ & 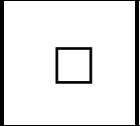 & [ & & L & 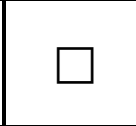 \\
\hline I show honest concern for my PSU friends' problems & $\square$ & $\square$ & $\square$ & $\square$ & $\square$ \\
\hline $\begin{array}{l}\text { I give my PSU friends good advice when they ask for } \\
\text { it }\end{array}$ & L & L & 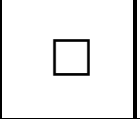 & $\square$ & 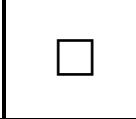 \\
\hline $\begin{array}{l}\text { I make it very easy to discuss my PSU friends' } \\
\text { personal feelings }\end{array}$ & L & & & L & L \\
\hline $\begin{array}{l}\text { I listen to my PSU friends' side of the story even if I } \\
\text { think that they are wrong }\end{array}$ & L & & & $\square$ & $\square$ \\
\hline $\begin{array}{l}\text { I make an effort to make my PSU friends feel better } \\
\text { when they are depressed }\end{array}$ & $\square$ & L & L & $\square$ & $\square$ \\
\hline
\end{tabular}


This is the last section. Now, please tell me a little about yourself.

What is your gender?

$\square$ Male

$\square$ Female

\section{7) Which year were you born?}

$<<$ choose the year from the pull-down menu $>>$

8) Which country are you from?

9) When did you start studying at PSU?

$<<$ choose the year from the pull-down menu $>>$

10) Which erm?

$\square$ Fall term

$\square$ Winter term

$\square$ Spring term

$\square$ Summer term

$\square$ Other (please specify)

If you selected other, please specify

11) Are you...?

$\square$ Studying at ESOL

$\square$ Undergraduate student

$\square$ Graduate student

$\square$ Other (please specify)

If you selected oher, pbase pecify 
12) Where do you live?

$\square$ On Campus (e.g. PSU housing, dormitory)

$\square$ Off campus (outside of PSU)

13) How many people do you live with? (Do not include yourself)

$\square$ 0 (alone)
$\square$ 1 person
$\square$ 2 people
$\square$ 3 people
$\square 4$ people
$\square$ 5 people
$\square 6$ people
$\square$ more than 7 people

14) Who are these people?

$\square$ my roommate / housemate
$\square$ my host family
$\square$ my boyfriend / girlfriend / romantic partner
$\square$ my spouse / domestic partner / family
$\square$ Other (please specify)

If you slected oher, pbase secify

15) Do you own a car in the U.S.?

$\square$ Yes

$\square$ No

16) Do you own a computer in the U.S.?

$\square$ Yes

$\square$ No 
17) Besides tuition for PSU, how much money do you need for living per month? (including housing, food, books, transportation, entertainment etc.)

$\square$ Less than $\$ 499$

$\square \$ 500$ to $\$ 999$

$\square 1000$ to $\$ 1499$

$\square 1500$ to $\$ 1999$

$\square$ More than $\$ 2000$

18) How often do you worry about your financial situation?

$\square 1$. Always worried

$\square$ 2. Often worried

$\square$ 3. Sometimes worried

$\square$ 4. Rarely worried

5. Not worried at all

19) Are you a native English speaker?
$\square$ Yes
$\square$ No

20) How comfortable are you when you talk in English?

$\square 1$. Very uncomfortable

$\square$ 2. Somewhat uncomfortable

3. Not sure

$\square$ 4. Somewhat comfortable

$\square$ 5. Very comfortable

21) Do you remember what your TOEFL/TOEIC scores are?

$\square$ Yes

$\square$ No 
22) What are your scores?

Internet-based score (iBT)

Computer-based score (CBT)

Paper-based score (PBT)

TOEIC score

Thank you for participating in the survey.

If you miss your friends in your home country and need some help, counseling services are available at Portland State University. You can call to the Center for Student Health and Counseling (503-725-2800), or stop by the clinic in UCB 200 (Monday - Thursday: 8am - 6pm, or Fridays: 8am to 5pm).

Students who are full time or part time and have paid the health fee are eligible to see a social worker, psychologist, or psychiatrist at no charge.

23)

You have a chance to win a $\mathbf{\$ 2 5}$ gift card for the PSU bookstore. Four participants will be chosen as winners by lottery. Even if you win the gift card, the researcher will not know who you are and what your answers are; you will be contacted by the Communication Department Office.

Would you like to join in the lottery? If so, please click the button. You just need to input your e-mail account.

$\square$ Yes, I would like to join

$\square$ No, I would not.

Thank you for your participation!! 